\title{
Current Understanding of Lifestyle and Environmental Factors and Risk of Non-Hodgkin Lymphoma: An Epidemiological Update
}

\author{
Bryan A. Bassig,, ${ }^{1}$ Qing Lan, ${ }^{2}$ Nathaniel Rothman, ${ }^{2}$ Yawei Zhang,, and Tongzhang Zheng ${ }^{1}$ \\ ${ }^{1}$ Division of Environmental Health Sciences, Yale School of Public Health, New Haven, CT 06510, USA \\ ${ }^{2}$ Occupational and Environmental Epidemiology Branch, Division of Cancer Epidemiology and Genetics, \\ National Cancer Institute, NIH, Bethesda, MD 20892, USA
}

Correspondence should be addressed to Tongzhang Zheng, tongzhang.zheng@yale.edu

Received 24 May 2012; Revised 20 July 2012; Accepted 4 August 2012

Academic Editor: P. Vineis

Copyright (C) 2012 Bryan A. Bassig et al. This is an open access article distributed under the Creative Commons Attribution License, which permits unrestricted use, distribution, and reproduction in any medium, provided the original work is properly cited.

The incidence rates of non-Hodgkin lymphoma (NHL) have steadily increased over the last several decades in the United States, and the temporal trends in incidence can only be partially explained by the HIV epidemic. In 1992, an international workshop sponsored by the United States National Cancer Institute concluded that there was an "emerging epidemic" of NHL and emphasized the need to investigate the factors responsible for the increasing incidence of this disease. Over the past two decades, numerous epidemiological studies have examined the risk factors for NHL, particularly for putative environmental and lifestyle risk factors, and international consortia have been established in order to investigate rare exposures and NHL subtypespecific associations. While few consistent risk factors for NHL aside from immunosuppression and certain infectious agents have emerged, suggestive associations with several lifestyle and environmental factors have been reported in epidemiologic studies. Further, increasing evidence has suggested that the effects of these and other exposures may be limited to or stronger for particular NHL subtypes. This paper examines the progress that has been made over the last twenty years in elucidating the etiology of NHL, with a primary emphasis on lifestyle factors and environmental exposures.

\section{Introduction}

Non-Hodgkin lymphoma (NHL) is a heterogeneous disease resulting from the malignant transformation of lymphocytes and includes multiple subtypes each with specific molecular and clinical characteristics [1]. The past several decades have seen a steady increase in incidence rates of NHL, with overall rates in the United States nearly doubling over the period 1975 to 2008 (Figure 1). Currently, incidence rates of NHL for both men and women in the United States are among the highest in the world (Figure 2) and, whereas rates of NHL associated with HIV infection have decreased with the use of antiretroviral therapy, there is evidence to suggest that rates from other causes have continued to increase $[2,3]$. In particular, distinct incidence trends have been reported among different demographic groups, as incidence rates decreased in middle-aged men starting in the mid 1990s, but increased in middle-aged women, blacks $\geq 55$ years old, and in younger whites aged 15-24 [4]. In 1992, an international workshop sponsored by the United States National Cancer Institute concluded that there was an "emerging epidemic" of NHL and the panel recommended investigation of the potential risk factors that were responsible for the rapid increase in this deadly disease [5].

Subsequently, over the ensuing two decades, tremendous efforts have been made to understand the risk factors accounting for the increase of NHL particularly as related to potential environmental and lifestyle risk factors. This effort has been aided by the initiation of several consortia, including a large international consortium of case-control studies (InterLymph) that has enabled a closer examination of NHL subtype-specific associations and the potential for etiologic heterogeneity as well as the assessment of less prevalent exposures $[1,6]$. Moreover, this research effort has been aided by the development of a uniform classification system for lymphoid neoplasms for use in epidemiologic 


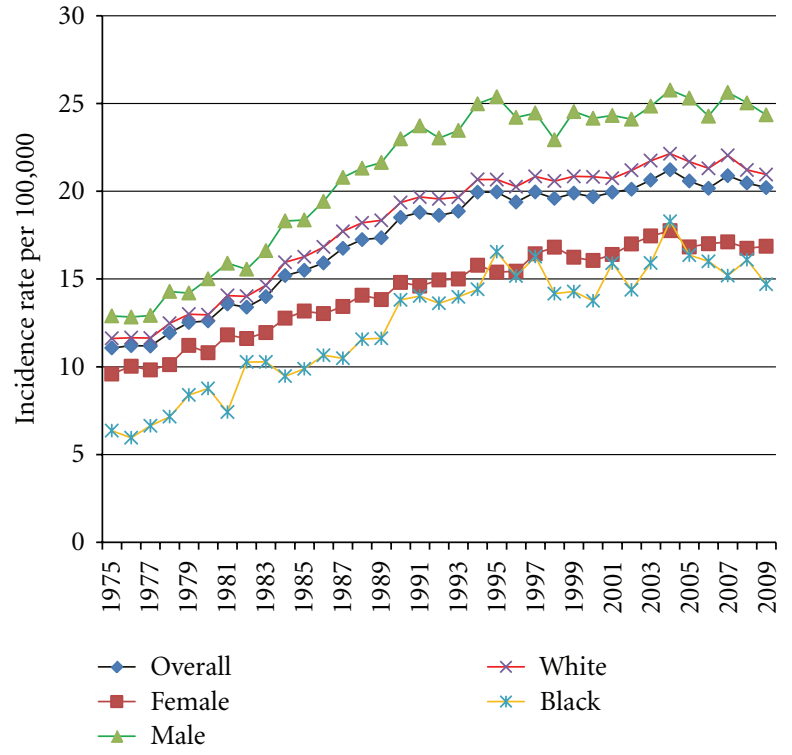

FIgURE 1: Temporal trends in the age-adjusted incidence rate of non-Hodgkin lymphoma in the United States based on SEER data, 1975-2009.

research by InterLymph, as several previous classifications have been developed and applied in studies including the Revised European-American Lymphoma classification in 1994 and the World Health Organization classification developed in 2001 and updated in 2008 [7]. Both the scientific community and the public must wonder where we are in terms of understanding the etiology of NHL after these twenty years of effort. Here, we summarize and review the epidemiological findings and progress that has been made over the past twenty years in terms of furthering our understanding of the etiology of NHL, with an emphasis on lifestyle and environmental risk factors that may contribute to NHL risk.

1.1. Smoking. Although the majority of epidemiologic studies do not support a major association between smoking and overall NHL [8-13], several studies which examined the risk for NHL subtypes suggest that smoking may increase the risk of follicular lymphoma (FL) [14-16]. The largest study that has examined an association with smoking to date, a pooled InterLymph analysis with 6,594 cases and 8,892 controls, reported an increased risk of FL in current smokers (OR 1.31, 95\% CI 1.12-1.52), including a 45\% increased risk in current heavy smokers, with some evidence for a doseresponse effect according to longer duration of smoking [15]. However, there was limited evidence for an effect with overall NHL for ever smoking (OR 1.07, 95\% CI 1.00-1.15; Table 1), and a significant FL association was not confirmed in the EpiLymph case-control study (Table 1) [17]. Cohort studies have been inconsistent with respect to the FL association, with three U.S. studies reporting elevated risks for either former, current smoking, or exposure to passive smoking $[16,18,19]$, and others reporting null or curiously decreased risks $[11,20,21]$.

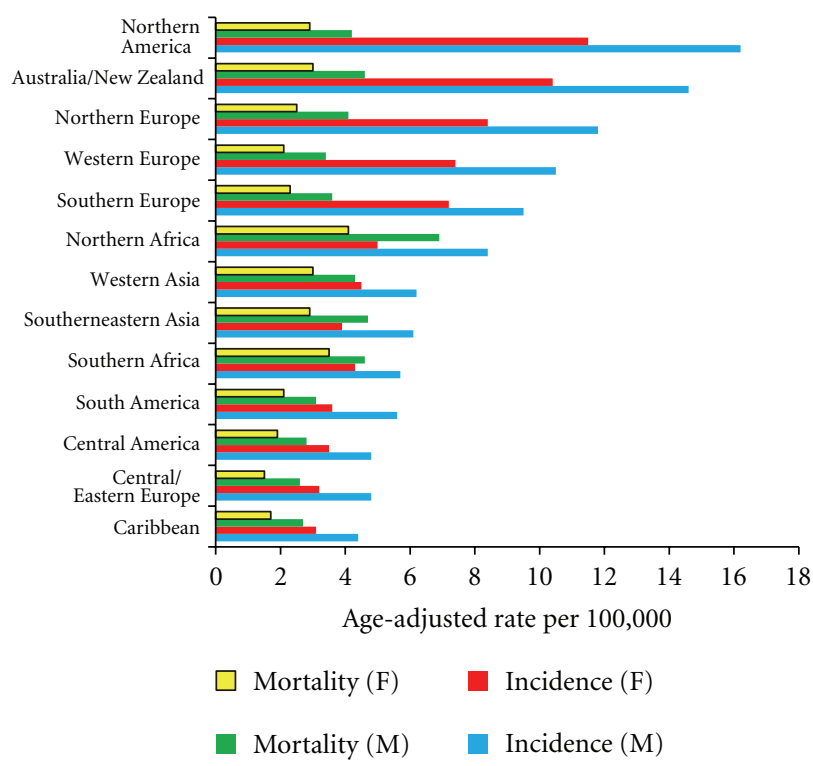

Figure 2: Age-adjusted incidence and mortality rates of nonHodgkin lymphoma in selected world regions based on IARC GLOBOCAN 2008 data.

An association with smoking and FL specifically may be biologically plausible, as heavy smoking has been observed in some studies to increase the risk of NHL associated with $\mathrm{t}(14$; 18) translocations, which are characteristic of FL and occur in up to $90 \%$ of cases $[29,30]$. Chronic exposure to cigarette smoke has been demonstrated to have immunosuppressive effects by impairing proliferation of $\mathrm{T}$ cells and antibody responses [31], but available evidence does not suggest that smoking is an important determinant for overall NHL risk.

1.2. Alcohol. A number of studies have examined the association between alcohol consumption and NHL risk, with some suggesting that consumption of alcohol may be protective against NHL $[8,21,22,32-35]$, but consistent epidemiological evidence for this protective association is lacking $[9,10,20,36-42]$.

Large international pooling studies have suggested an overall reduced risk of NHL associated with alcohol consumption or in distinct subgroups. An InterLymph study that included 6,492 NHL cases and 8,683 controls (Table 1) reported a modest reduced risk of NHL in ever drinkers (OR 0.83, 95\% CI 0.76-0.89) but no clear dose-response trends [22], and a large EpiLymph study including 1,742 cases and 2,465 controls reported a protective effect in male ever drinkers (OR $0.76,95 \%$ CI $0.62-0.93$ ), but no overall effect was observed (Table 1) [17]. Two large cohort studies have shown some evidence for an inverse association with the DLBCL subtype, but were conflicting with respect to overall NHL risk [20, 21]. Most recently, a systematic review of 29 studies has indicated an overall reduced risk of NHL for drinkers compared to nondrinkers (RR $0.85,95 \%$ CI 0.79-0.91), with similar risk estimates for the level (i.e., light, moderate, and heavy) of consumption [43]. 


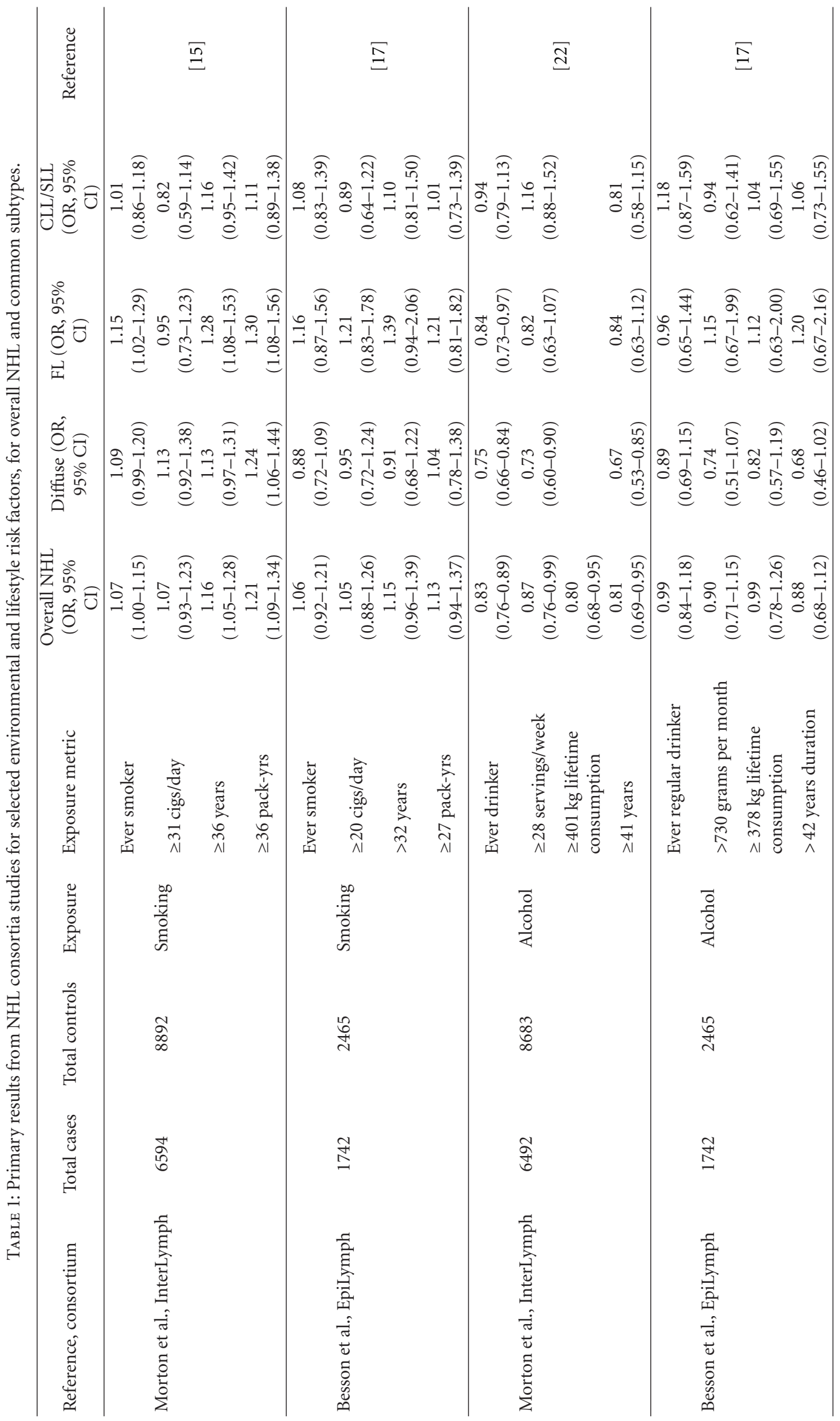




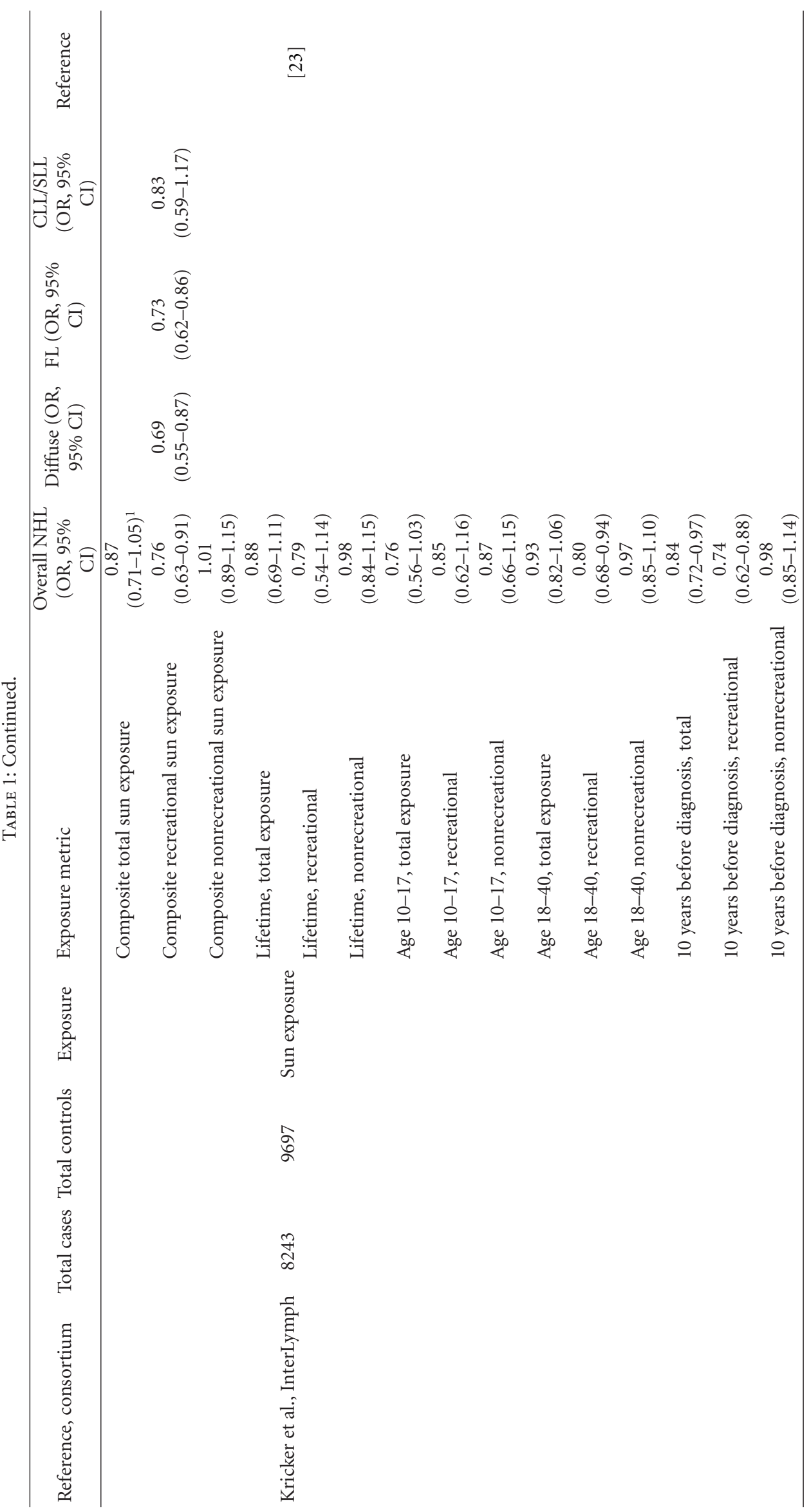




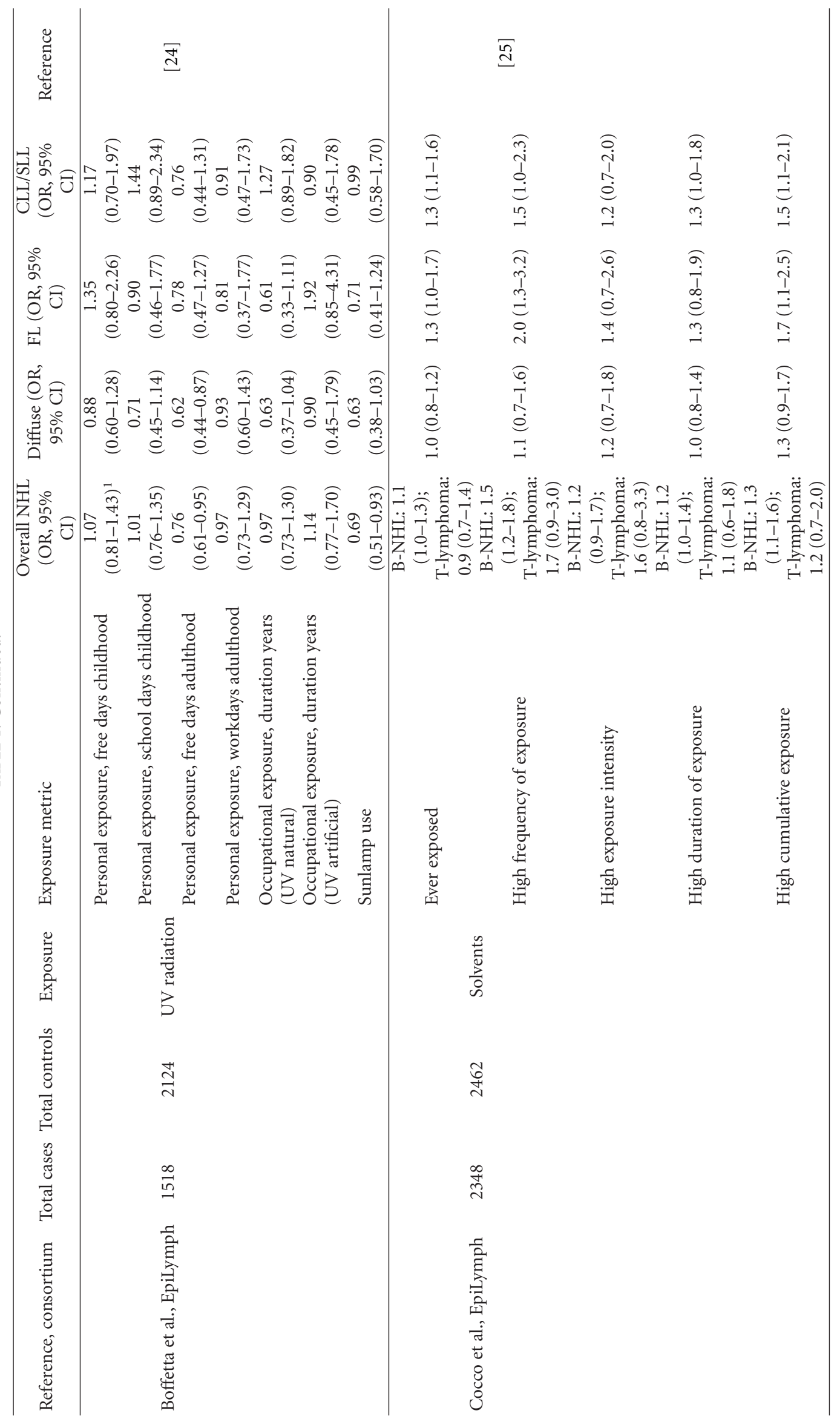




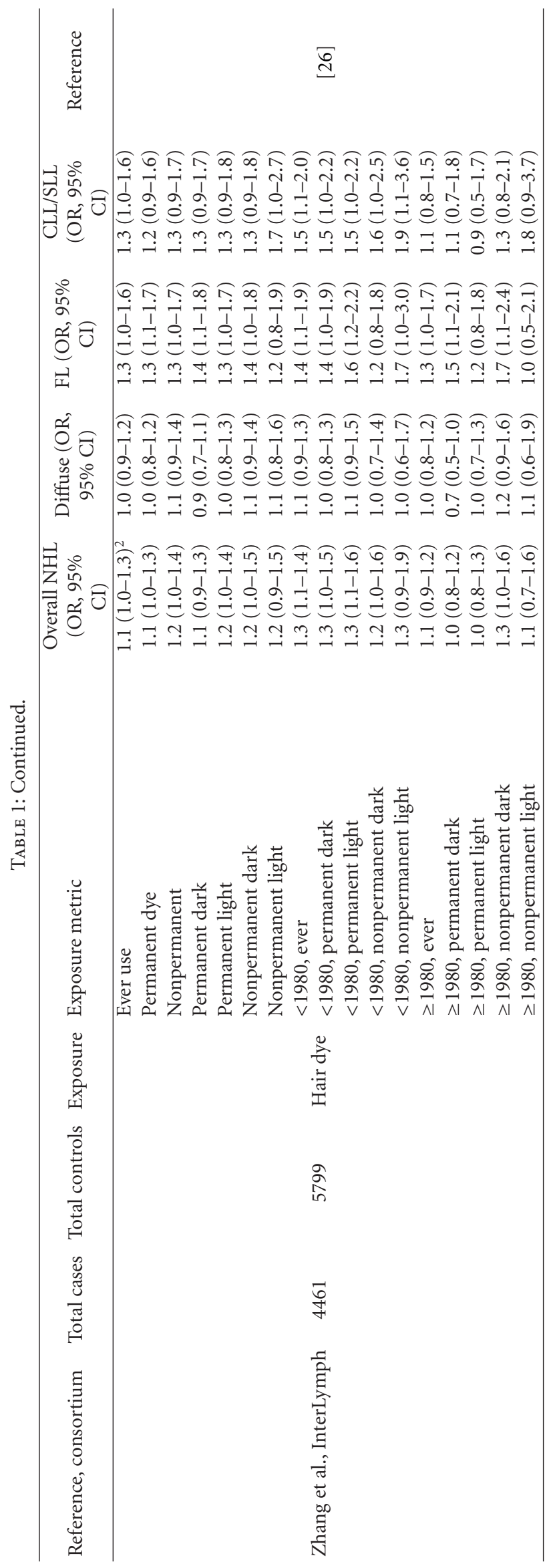




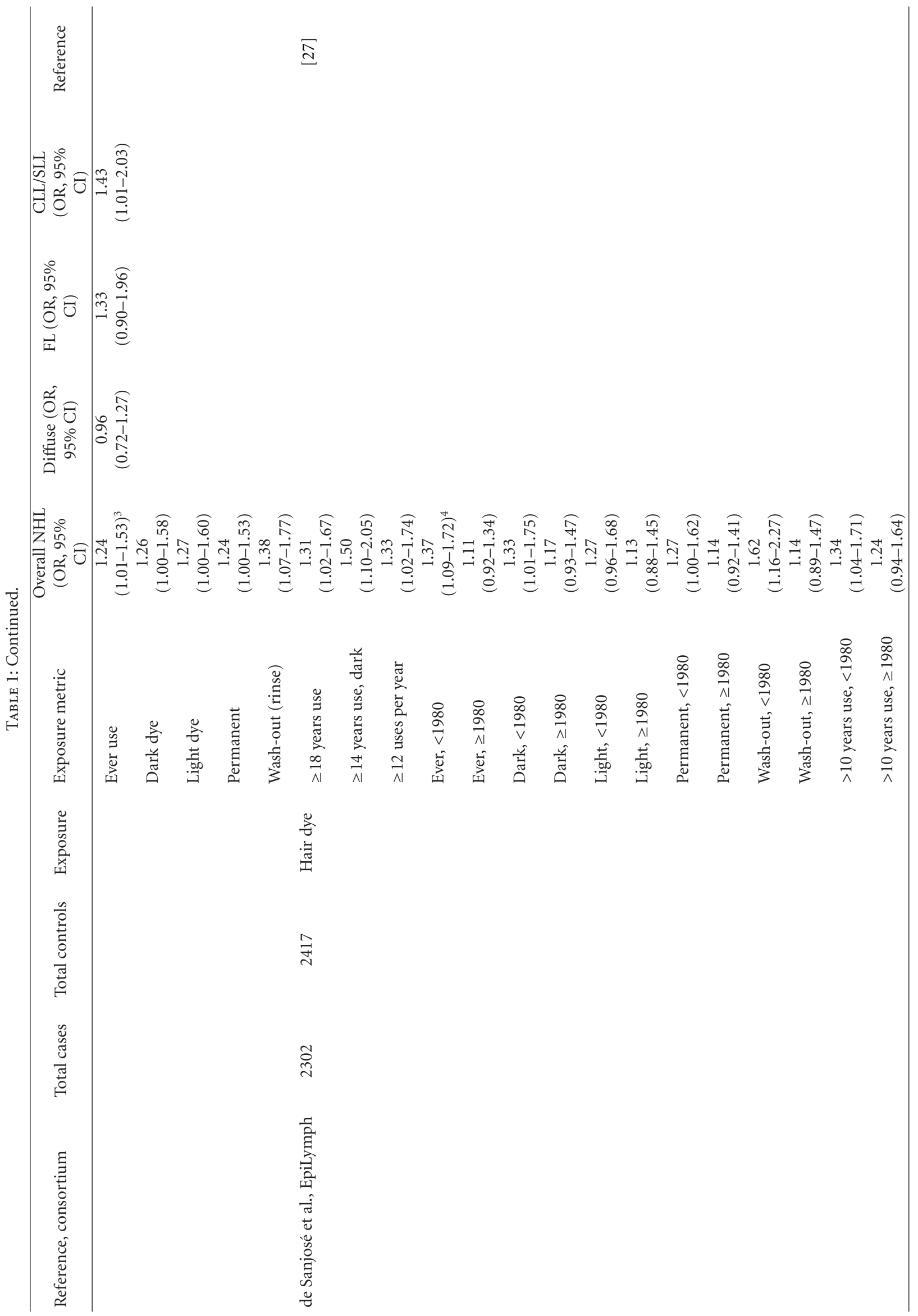




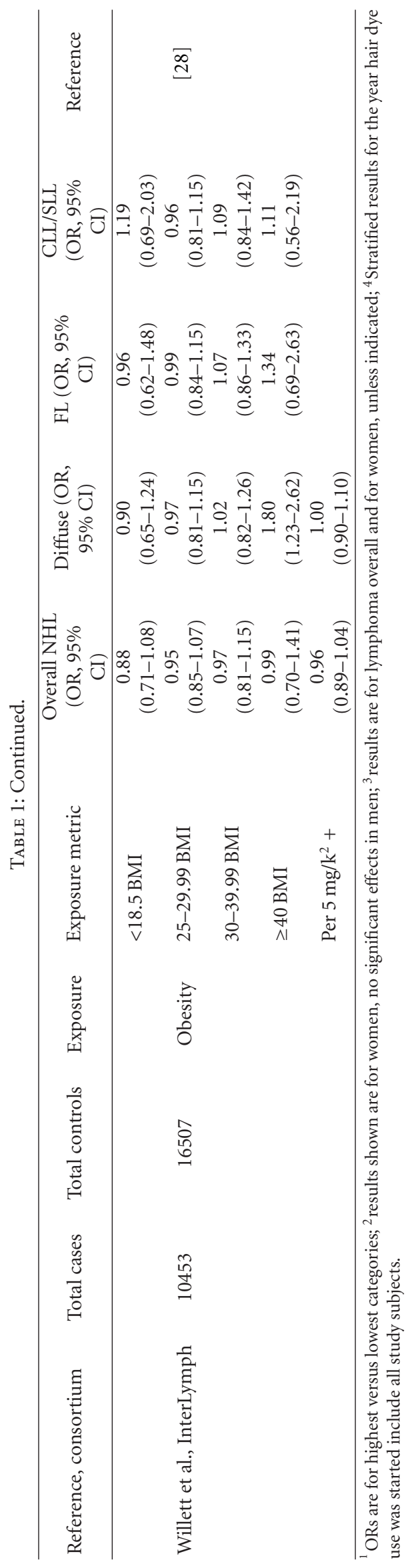


The suggested reduced risk of NHL associated with alcohol consumption has varied in some studies by alcoholic beverage type. Studies conducted in Connecticut and among women living in Iowa, for instance, have suggested decreased risks of NHL associated with higher consumption of red wine $[33,44]$. Higher consumption of wine has also been inversely associated with NHL in a large population-based case-control study [45], but other studies suggest null or elevated risks $[10,20,40]$. Red wine is a source of a variety of phytochemicals, including resveratrol which has antiinflammatory properties and may aid in the inhibition of tumor proliferation [46], including for human lymphoma cells specifically [47].

Low-to-moderate alcohol intake may increase immunocompetence by improving humoral and cellular immunity [48], but an association with NHL to date has not yet been firmly established. Additional epidemiological evidence with respect to potential dose-response effects and the relevant quantity of consumption that may be most relevant in terms of risk is needed.

1.3. Hair Dye. Several case-control studies that have collected comprehensive exposure data and disease information have indicated that the risk of NHL associated with hair coloring product use may vary by the type of dye products, time period of use, and the duration and intensity of the products used $[26,27,49,50]$. Further, the risk appears to vary by NHL subtype.

For example, several studies have indicated that an increased risk of lymphoma and/or NHL specifically is apparent in people who started using hair dye before the year 1980, with the highest risks for greater numbers of applications and at least 25 years of use [26, 27, 49]. An increased risk was seen among permanent or dark colored dye users and for the FL and CLL subtypes. These findings have been reported by a large pooled InterLymph study of 4,461 cases and 5,799 controls (Table 1), which found elevated risks of FL (ever use < 1980, OR 1.4, 95\% CI 1.1-1.9) and CLL/SLL (ever use <1980, OR 1.5, 95\% CI 1.1-2.0), but not for other subtypes, primarily in women who started use before 1980 [26]. This observation, and given that patterns of use may vary over time, has underscored the need to comprehensively examine lifetime use of hair dye products, and studies which do so may provide the best assessment of its etiologic role.

Several studies, including prospective cohorts, which investigated this relationship have not reported an increased risk of NHL for hair dye use, but not all of these studies collected detailed information on lifetime hair dye use and the data usually did not allow for comprehensive examination of the risk by exposure features (such as by time period of use, type and color of products, and lifetime duration of use) and subtypes of the disease [38, 51, 52].

Hair dye formulations have long been known to contain mutagenic chemicals [53] including aromatic amines, and formulations prior to 1980 likely contained greater amounts of these chemicals. This is notable given that chromosomal aberrations which may arise from mutagenic exposures are characteristic of both CLL and FL. While the absence of a consistent risk after 1980 may be reflective of regulatory requirements imposing stricter safety standards on hair dye products, it is also plausible that the induction period for carcinogenicity has not yet manifested to detect elevated risks in more recent users. This would suggest the urgent need for continued studies of more recent users to further characterize this risk.

\subsection{Radiation}

1.4.1. UV Radiation. Several lines of evidence have emerged suggesting that exposure to ultraviolet (UV) radiation may be associated with NHL risk. In addition to parallel increases in incidence of NHL and cutaneous melanoma in the United States since the 1980s, several studies have reported an increased risk of NHL associated with a previous skin cancer, including melanoma, suggesting the possibility of a common risk factor [54-57]. Second, one of the highest incidence rates of NHL in the world is found in Australia, which has high UV exposure and also one of the highest rates of melanoma globally. Moreover, experimental evidence has demonstrated that UV radiation at high levels may suppress the immune response [58] and decrease levels of betacarotene, which has immunostimulatory properties and may enhance lymphocyte functioning $[59,60]$. Finally, a series of ecologic studies have noted positive correlations between NHL incidence and ambient UV radiation exposure [61, 62] though this evidence has been inconsistent [63, 64]. Moreover, increasing sun exposure and residence in southern most latitudes have been associated with an increased risk of NHL in a study of Connecticut women (OR 1.7, 95\% CI $1.2-2.4$ ) and in a Swedish cohort (RR 1.21, 95\% CI 1.08$1.35)$, respectively $[65,66]$. Similar results were suggested in a recent study from the Nurses' Health Cohort, which found an increased risk of NHL associated with high ambient UV radiation exposure [67].

Conversely, the majority of epidemiological studies have reported a decreased risk of NHL for various measures of sun exposure although differences in exposure assessment and constructs of sun exposure across studies may limit comparative interpretations [68-74]. A significantly reduced risk of NHL or specific B-cell subtypes with increasing recreational exposure to the sun was reported in both InterLymph (OR 0.76, 95\% CI 0.63-0.91) and EpiLymph consortia studies (OR for DLBCL, 0.62, 95\% CI 0.44-0.87), which had the power to consider multiple NHL subtypes and constructs of exposure (Table 1) [23, 24]. A further protective effect for DLBCL which was marginally significant was reported in the EpiLymph study for greater use of sunlamps (OR $0.63,95 \%$ CI $0.38-1.03$ ) and for longer duration of occupational sun exposure.

The primary hypothesis for a protective effect of sunlight, if real, has focused on the potential role of vitamin D absorbed from sunlight, which has been demonstrated to induce regression of low-grade NHL and possess antiproliferative effects in lymphoma cell lines [75]. There is no consistent evidence, however, suggesting that either dietary 
vitamin $\mathrm{D}$ or circulating levels of 25-hydroxyvitamin D, the main vitamin D metabolite, is associated with NHL $[67,76-78]$. Alternative hypotheses have focused on the role of ultraviolet radiation and its effect on the Th1-Th2 mediated immune response, but further elucidation of this potential mechanism is needed [76, 79]. Importantly, the underlying biological mechanism as well as clarification as to why regions with high UV radiation exposure report higher rates of NHL will require further study in order to support any epidemiological findings of a protective effect for sunlight.

1.4.2. Ionizing Radiation. There is limited evidence to suggest that exposure to ionizing radiation is a major risk factor for NHL. Analyses of cancer incidence and mortality within the U.S. radiologic technologists' cohort, which includes followup of more than 100,000 workers, have generally not reported an excess risk of NHL in these workers who are exposed to low-levels of radiation on a chronic basis [8082]. Further, no consistent risk associated with diagnostic or therapeutic radiation [83-86] or occupational exposures has emerged [87-90].

The survivors of the Nagasaki and Hiroshima bombings, who received both large and acute doses of radiation, also showed no excesses of malignant lymphoma in all cases $[91,92]$, while excess relative rates of NHL mortality were recently observed for those with the longest time period since exposure, suggesting that any lymphomagenic effect of ionizing radiation may have a long induction period [93]. An elevated risk for mortality and NHL incidence has also been reported in a cohort of British radiologists [94] and in patients receiving radiotherapy for ankylosing spondylitis (RR 1.74, 95\% CI 1.23-2.36), respectively [95]. NHL has been observed to occur as a second primary cancer; however, the relative contribution of radiotherapy, chemotherapy, or a general susceptibility to lymphoma has been debated [96]. Given limited evidence and the relatively infrequent exposures to high levels of ionizing radiation in the overall population, any contribution of this exposure to the overall rise in NHL rates is likely to be small.

\subsection{Diet}

1.5.1. Macronutrients. The role of dietary intake and lymphomagenesis has been reviewed elsewhere [97]. Briefly, of the macronutrients, a higher intake of dietary fat has been associated with NHL, including total, saturated, and animal fat, and to a lesser extent monounsaturated fat [98-101]. Two large cohort studies in the United States, including one of women in Iowa and the Nurses' Health Cohort, have reported an increased risk of NHL for higher levels of animal fat (RR 2.00, 95\% CI 1.21-3.30), saturated fat (RR 1.69, 95\% CI 1.07-2.67), monounsaturated fat (RR 1.90, 95\% CI 1.18-3.04), and transunsaturated fat (RR 2.4, 95\% CI 1.3-4.6) [99, 100]. The association for NHL with protein intake is inconclusive, as null results [98-100] have been reported in addition to two population-based casecontrol studies in the U.S. which have reported conflicting findings for total protein $[101,102]$. Intake of animal protein has been suggested to influence immune functioning, but epidemiologic evidence has not been consistent with respect to NHL risk [98-101]. There is limited evidence to suggest that higher intake of carbohydrates is associated with NHL, although a positive association has been observed for Bcell lymphoma specifically (OR 1.4, 95\% CI 1.0-2.0) as well as for higher intake of dessert foods for overall NHL $[98,101]$.

1.5.2. Micronutrients. Antioxidants have a recognized benefit to the immune system including protection from the effects of free radicals and oxidative stress [103], and deficiencies in specific nutrients involved in one-carbon metabolism, in particular, may lead to disruption in DNA repair processes [104]. However, a series of epidemiological studies including prospective cohorts have not suggested consistent protective effects for NHL and intake of specific vitamins, or for multivitamin use $[99,101,105-108]$. It is possible that any protective effect of vitamin use may be subtype-specific, as a decreased risk of FL was observed with greater intake of dietary vitamin C (RR 0.55, 95\% CI 0.30-1.00) in a large prospective study of Iowa women [109].

Associations with micronutrients involved in one-carbon metabolism have been shown, but have differed with respect to the specific nutrient. Whereas dietary $\mathrm{B}_{12}$ was inversely associated with NHL risk in male smokers enrolled in the Alpha-Tocopherol Beta-Carotene prevention trial (HR 0.61, 95\% CI 0.37-1.00) [110], this finding was not confirmed in three case-control studies each of which found protective associations for higher intake of either vitamin $\mathrm{B}_{6}$, methionine, and folate either overall or in specific subgroups (i.e., alcohol abstainers) [111-113]. It is likely that the risk associated with these micronutrients may be modified by other exposures, including consumption of alcohol [113], or by genetic susceptibility and/or gene-environment interactions involving one-carbon metabolism genes [114]. Relative to vitamin intake, the association between other micronutrients and NHL has received less attention, although evidence from the Iowa Women's Health Cohort has suggested a potential protective effect of other antioxidants including dietary manganese, proanthocyanidins, and alpha-carotene [109].

1.5.3. Specific Food Items. Overall, few dietary components have emerged as strong and consistent risk factors for NHL, although some suggestive associations have been identified and reviewed [97]. Briefly, some epidemiological studies have inconsistently reported an elevated risk of NHL for red meat intake, or specific types of meat, as well as for overall or specific types of dairy food, but these findings have not been consistent [97]. Depending on the preparatory method, red meat specifically is a source of several mutagenic compounds and, in the case of processed meat, of $N$-nitroso compounds. However, some studies which have considered associations with well-done meat and levels of specific mutagens have generally not supported a clear risk, but some evidence has indicated that intake of broiled meat may be associated with 
a greater risk of NHL compared with other preparatory methods $[100,102]$.

Conversely, the strongest evidence for a decreased risk of NHL has been higher intake of some vegetables and fruits, particularly for cruciferous vegetables [97]. Several large cohorts, including one of over 35,000 women in Iowa and among 88,410 subjects enrolled in the Nurses' Health Cohort, have reported a decreased risk of NHL associated with the highest intake of all fruits and vegetables (RR $0.69,95 \%$ CI $0.51-0.94$ ) and greater consumption of fruits and cruciferous vegetables $[106,109]$. These findings are biologically plausible given that cruciferous vegetables and some fruits are rich sources of antioxidants and folate, and constituents of cruciferous vegetables may aid in the metabolism of carcinogens via interaction with drug metabolizing enzymes [115].

1.6. Occupation. Conclusions from studies examining the role of occupational groups and NHL risk are generally limited by the small number of individuals in specific occupations as well as a general inability to collect individual level data on working patterns and potential exposure profiles. However, these studies can be useful in terms of gaining insight into potential etiological factors, particularly for chemical exposures.

The strongest evidence for an elevated risk of NHL for a specific occupational group is for farmers or agricultural workers [90, 116-121], suggesting a potential chemical or viral etiology. These associations have been subsequently observed in several, but not all [122] meta-analyses, with relatively modest elevated risks [116, 123, 124]. Aside from chemical exposures, some evidence has indicated that contact with animals and/or animal breeding may contribute to NHL risk or mortality $[116,119,125,126]$. In a metaanalysis conducted by Boffetta and de Vocht, associations with NHL for farming were predominately limited to studies which examined animal breeding, suggesting a potential importance of viral exposures [116].

Both primary and secondary teachers have been reported to have elevated risks of NHL, which is thought to be due primarily to exposure to childhood infections $[116,118$, 127]. However, effects for other occupational groups have been largely inconsistent. Inconsistently elevated risks have been reported for metal workers [117, 118, 128, 129], meat or food production workers [117, 130-132], mechanics/and or truck drivers $[117,118,130]$, wood workers $[116,129]$, communication workers $[118,133,134]$, workers in the printing industry $[116,118]$ as well as a variety of workers in the service industry or in white-collar professions [128, 133-136].

The meta-analysis conducted by Boffetta and de Vocht examined seven occupational groups that have emerged from epidemiological studies as potentially related to NHL risk [116]. In addition to farming and teaching, livestock workers (RR 1.31, 95\% CI 1.08-1.50), printers (RR 1.86, 95\% CI 1.37-2.52), and wood workers (RR 1.15, 95\% CI 1.00-1.31) all had significantly increased associations with NHL. Further, in a recent examination of occupation in the European Prospective Investigation into Cancer and
Nutrition cohort, butchers and car repair workers were the only occupational groups that showed an increased risk of NHL [130]. Given the lack of established environmental risk factors for NHL, the implications of these findings are not yet clear, though exposures to solvents or other chemicals may be implicated.

\subsection{Chemical Exposures}

1.7.1. Solvents. Results from several epidemiological studies have indicated that exposure to solvents may increase overall NHL risk or for specific subtypes [25, 131, 137-145]. A large pooled case-control study in Europe has reported elevated risks for FL (OR 1.3, 95\% CI 1.0-1.7) and CLL (OR 1.3, 95\% CI 1.1-1.6; Table 1) for ever solvent exposure with risks varying for specific chemicals [25]. Risk estimates for NHL and overall solvent exposure are likely to mask chemical specific associations, given that some but not all solvents may be associated with NHL.

Two of the most widely studied chemicals with respect to NHL risk have been benzene and trichloroethylene (TCE), which have a number of industrial uses and applications. Overall, some suggestive evidence has emerged for an association with NHL for benzene exposure based on animal studies, case-control studies of benzene exposure, and some occupational cohorts, but the evidence is inconsistent and several meta-analyses have reported conflicting findings [137, 146-149]. Findings from the Pliofilm cohort of rubber workers, which suggested a significantly elevated association with leukemia mortality and has played a role in the development of occupational benzene exposure standards, did not report an association with NHL mortality (SMR $=0.96,95 \%$ CI 0.31-2.25) [150]. A common limitation of occupational studies of solvent exposure more generally and benzene in particular is the potential for exposure misclassification, which may arise from reliance on self-reported work histories or assigning levels of exposure based solely on job title. Furthermore, it is likely that any effect of benzene exposure on NHL risk could be subtype-specific, which may not be apparent in analyses which consider NHL overall. Some analyses have supported these possibilities, suggesting a significantly elevated risk of NHL after taking into account studies with likely exposure misclassification as well as for the CLL subtype specifically in an analysis of occupational cohorts which evaluated study quality $[151,152]$.

Similar methodologic issues have limited firm conclusions regarding the association between TCE exposure and NHL. Specifically, occupational cohorts that have examined this association have varied with respect to the quality of the exposure assessment with methods ranging from the use of urinary biomarkers of exposure and job exposure matrices (JEMs) to evaluations based solely on job title. Further, the majority of studies have not considered specific NHL subtypes, have had a relatively small number of exposed cases, and have used different NHL classification systems [153]. One of the larger occupational cohort studies which included 40,049 blue-collar workers (96 NHL cases) in Denmark reported a $50 \%$ elevated risk of NHL in a 
subcohort of workers with the highest assumed exposures to TCE [154], while other cohorts including those which utilized urinary biomarkers of exposure have not consistently reported significantly elevated associations [155-158]. Metaanalyses that have stratified studies based on the quality of the exposure assessment or overall study quality provided some indication for an elevated risk of NHL in studies with more extensive exposure assessment, but clear doseresponse trends were lacking and there was no assessment of subtype-specific associations [159, 160]. These studies which suggested a positive association tended to have more detailed exposure assessments such as having a subcohort of workers who were more likely to be exposed or utilized biomarkers or JEMs, compared to less specific studies which relied on occupation or lacked verification of TCE exposure specifically $[159,160]$. More recently, findings from a NCISurveillance, Epidemiology and End Results case-control study which had detailed exposure assessment suggested a 2.5-fold increased risk of NHL in workers with the highest category of average weekly TCE exposure as well as for the highest cumulative exposure, and elevated associations were seen for both FL and CLL/SLL [161]. This study utilized jobspecific exposure modules and evaluated multiple metrics of TCE exposure including duration, average weekly and cumulative exposure levels, in addition to considering the probability of exposure.

Recent molecular epidemiology studies of TCE and benzene exposures have suggested that each of these chemicals results in hematotoxic and/or immunotoxic effects that may be relevant to lymphomagenesis, indicating that an association with NHL may be biologically plausible. Specifically, declines in peripheral blood cell counts and lymphocyte subsets, including $\mathrm{CD}^{+} \mathrm{T}$ cells, have been observed in workers exposed to both benzene and TCE, indicating the ability of these chemicals to result in immunosuppressive effects $[162,163]$. Further, TCE exposure has been demonstrated to result in alterations in several immune parameters, including blood cytokine levels and markers of B-cell activation, and has been previously associated with the development of some autoimmune conditions $[162,164]$.

1.7.2. Pesticides. Epidemiological studies of pesticide exposure and NHL risk have generally focused on specific classes of pesticides, including organochlorine pesticides (OCPs), organophosphates (OPs), and carbamate insecticides. Some OCPs have been demonstrated to be genotoxic in animal and in vitro models $[165,166]$, but the epidemiological results for specific OCPs have been mixed. Specifically, whereas positive associations with NHL for use of DDT [167-169], oxychlordane $[170,171]$, and $p, p^{\prime}$-DDE levels in serum and adipose tissue have been reported $[170,171]$, others have not observed an association with NHL for DDT or other OCPs [172-175]. An analysis of serum $p, p^{\prime}$-DDE levels using data from three large cohorts provided some evidence for a positive association with NHL, but there were no clear dose-response trends and results were attenuated after adjustment for levels of PCBs [176].
These differences across studies may be partially explained by the use of different biologic specimens, as adipose tissue is thought to better reflect cumulative exposure levels than serum, particularly with respect to DDT and its metabolites. A recent Danish cohort study, for instance, found a positive association for NHL with increasing adipose tissue levels of DDT (IRR 1.35, 95\% 1.10-1.66) in prediagnostic samples [177]. Another limitation inherent to studies of pesticide exposure is the potential for confounding by coexposures due to use of multiple chemicals. De Roos and colleagues analyzed a series of 47 pesticides simultaneously in a pooled study of 650 cases and 1933 controls using data from three case-control studies in the United States that assessed pesticide exposure using direct subject interviews. Among the OCPs, elevated but nonsignificant associations with NHL were reported for chlordane and dieldrin, but not for DDT or other OCPs [178].

Similarly inconsistent findings for NHL risk have been observed for other classes of pesticides. Experimental evidence has suggested that some OPs and carbamate insecticides may be genotoxic and potentially immunotoxic, and in the case of OPs may induce chromosomal damage at domestically sprayed levels $[179,180]$. Evidence for an association with NHL for OP insecticides has come from a pooled study of 748 cases and 2,236 population-based controls (OR 1.5, 95\% CI 1.2-1.9), although the highest risks were associated with cases who had proxy interviews [181], as well as in two population-based case-control studies $[167,168]$ where use of any OP insecticide was positively associated with NHL risk. Moreover, the pooled case-control study conducted by De Roos and colleagues has reported an elevated risk of NHL for the OP insecticides coumaphos (OR 2.4, 95\% CI 1.0-2.58), diazinon (OR 1.9, 95\% CI 1.1-3.6), and fonofos (OR 1.8, 95\% CI 0.9-3.5) [178].

With respect to carbamate exposure, an elevated risk of NHL in farmers who used carbamate herbicides (OR 1.5, 95\% CI 1.1-2.3) or insecticides (OR 1.6, 95\% CI 1.2-2.2) was reported in a large pooled study, with the strongest evidence for carbaryl [182]. This finding is consistent with two studies in Canada and Italy, each of which reported about a twofold increased risk of NHL for carbaryl exposure $[168,183]$. However, there was no clear association among over 21,000 subjects in the Agricultural Health Study [184]. Carbaryl has shown little genotoxic potential in humans; however, immunotoxic effects have been demonstrated in animal models [185].

Use of phenoxyacetic acid (PCA) and triazine herbicides has each been studied with respect to NHL risk, with inconsistent findings. In De Roos et al.'s evaluation of 47 pesticides, no association with individual PCA herbicides was observed, but an elevated risk of NHL for use of the triazine herbicide atrazine (OR 1.6, 95\% CI 1.1-2.5) was reported [178]. Further, an elevated risk of NHL for exposure to 2,4-D and/or 2-methyl-4-chlorophenoxyacetic acid (MCPA), two PCA herbicides, has been observed [168, 186-188], including in a Swedish case-control study of 910 cases and 1,016 controls where an elevated risk of NHL for use of MCPA was reported (OR 2.81, 95\% CI 1.27-6.22) in addition to the herbicide glyphosate (OR 2.02, 95\% CI 
1.10-3.71) [187]. However, the association with NHL for use of atrazine was not confirmed in the Agricultural Health Study nor in two large case-control studies $[167,183,189$, 190].

Overall, studies of pesticide use are generally limited by small sample sizes, the presence of multiple coexposures, lack of detailed information on exposure histories, and in some instances the use of a proxy for exposure assessment. These methodological challenges have likely contributed to the overall inconsistent findings concerning pesticide use and NHL risk, but reports of an elevated risk for some pesticide classes suggest that an association cannot be ruled out.

1.7.3. Polychlorinated Biphenyls (PCBs). Several studies have evaluated the association between total PCB exposure and NHL, as well as for specific congeners, and these associations have been reviewed elsewhere [191]. PCBs were used extensively in industry starting in the 1930s and continuing through the 1970s, after which their use was banned by the U.S. Environmental Protection Agency. However, the relative stability and bioaccumulation of these compounds, as well as the immunotoxic potential of some PCB congeners, has raised some concern about lasting health effects [191]. Currently, PCBs are classified as probable carcinogens (group 2A) by the International Agency for Research on Cancer.

Two nested case-control studies, including one which pooled data from three existing cohorts, have reported an increased risk of NHL associated with total serum or plasma levels of PCBs, or exposure-response trends for the congeners 118,138 , and 153 in all three cohorts $[176,192]$. Further, a case-control study of 100 cases and 100 controls in the United States which evaluated NHL risk in relation to specific PCB congeners reported an elevated risk for PCBs 156 (OR 2.70, 95\% CI 0.97-7.50), 180 (OR 3.50, 95\% CI 1.34-9.15), and 194 (OR 3.52, 95\% CI 1.30-9.52) [193]. However, a nested case-control study using data from the Nurses' Health Cohort, as well as two other case-control studies and a Danish cohort study, reported no association for total PCB exposure or for individual congeners in blood or adipose tissue samples [170, 172, 174, 177].

While several of the specific PCB congeners that have been reported to increase NHL risk are potentially immunotoxic [194], thus supporting a potential etiologic role, correlation between individual congeners and with some organochlorine pesticides as well as limited evidence concerning the most relevant time period of exposure necessitates further followup of these findings.

\section{Medical Risk Factors}

In addition to immune deficiency, and evidence suggesting that a family history of a hematologic cancer is positively associated with NHL risk [195-197], several other medical risk factors have been identified for NHL. Here, we provide a general and brief overview of these conditions that have been implicated in NHL risk.
2.1. Infectious Agents. Infectious causes of NHL have been extensively reviewed elsewhere [198]. Infection with HIV is the most well-characterized infectious risk factor for NHL, with elevated risks nearing four-hundred fold for certain subtypes although rates of AIDS-related NHL have declined with the emergence of antiretroviral therapy $[199,200]$. AIDS-related NHL results from systemic immunosuppression and chronic B-cell stimulation, with the majority being high-grade tumors and involving extra nodal sites [201]. AIDS-NHL are pathologically heterogeneous and include high-grade B cell lymphomas that also manifest in HIV negative patients, and subtypes that are more specific to HIV, including primary effusion lymphoma and plasmablastic lymphoma of the oral cavity [202]. Levels of B-cell stimulatory biomarkers suggestive of immune activation are elevated preceding a systemic AIDS-NHL diagnosis, indicating that chronic stimulation of B cells associated with HIV/AIDS may contribute to AIDS-related tumors [203]. Overall, current $\mathrm{CD}^{+} \mathrm{T}$-cell count as well as the duration of time spent with a high viral load are important predictors of AIDS-NHL risk [204].

Other than HIV, infection with Epstein-Barr virus (EBV) is associated with NHL in the context of immunosuppression resulting in proliferation of transformed B cells normally controlled by T-cell-mediated immunity [205]. About half of DLBCL cases in the context of HIV infection are EBV positive, whereas about $30 \%$ of Burkitt's lymphoma are EBV associated [206]. In immunocompetant hosts, EBV is associated with rarer NK/T cell subtypes, and nearly all cases (>95\%) of endemic Burkitt's lymphoma in Northern Africa are EBV positive [207]. Recently, a large InterLymph analysis with 12,585 NHL cases and 15,416 controls reported an excess risk of NHL associated with a self-reported history of infectious mononucleosis (OR 1.26, 95\% CI 1.01-1.57), of which EBV is a major cause, and particularly for CLL and T-cell NHL, but this history was based on self-report and there was significant heterogeneity across studies [208]. A similar increase in risk for NHL, B-cell lymphoma, and CLL/SLL was reported for a self-reported history of infectious mononucleosis among 2,362 lymphoma cases and 2,458 controls in the EpiLymph study [209].

Moreover, infection with human T-lymphotropic virus 1 (HTLV-1) and human herpesvirus-8 (HHV-8) has been associated with rare NHL subtypes. Specifically, a lifetime cumulative risk of developing adult T-cell leukemia/lymphoma (ATL) on the order of $2-6 \%$ has been observed among HTLV-1 carriers in Japan [210], while infection with HHV8 is associated with Kaposi's sarcoma as well as body cavity lymphoma and primary effusion lymphomas in the setting of immunodeficiency [211,212].

Increasing evidence has suggested that hepatitis $\mathrm{C}$ infection (HCV) may increase the risk of NHL [213-215], but a causal relationship is not conclusive [216, 217], and some evidence also indicates a potential etiologic role of hepatitis B [209, 213]. An elevated risk of NHL as well as for several subtypes associated with HCV was observed in a large population-based SEER study of 61,464 cases of hematopoietic malignancies (OR 1.35, 95\% CI 1.06-1.73), as well as in a meta-analysis of 18 studies which included 
$\geq 100$ cases ( $R R$ 2.5, 95\% CI 2.1-3.1), with consistent risks for B-and T-cell subtypes $[218,219]$. Further, a large pooled InterLymph study including 4,784 cases and 6,269 controls found an elevated risk of primarily B-cell subtypes, including DLBCL and marginal zone lymphoma, associated with HCV infection [220]. Notably, complete or partial remission of lymphoproliferative disorder has been observed following antiviral therapy for $\mathrm{HCV}$ in up to $75 \%$ of cases, which provides some plausibility for the positive epidemiologic findings [221].

H. pylori infection is a causative agent of gastric MALT lymphoma, an indolent tumor arising from B cells and affecting the gastric mucosa. Chronic inflammation due to infection results in the colonization and proliferation of lymphocytes in the gastric mucosa; however, only a small percentage of $H$. pylori positive individuals develop MALT lymphoma [222]. H. pylori infection has been reported to increase the risk of gastric MALT lymphoma specifically by about sixfold [223]. A high percentage of patients with this rare subtype, up to $98 \%$, are found to be infected with $H$. pylori, and eradication of infection leads to complete remission of early-stage lymphoma in up to $80 \%$ of cases [224]. As reported in a population-based study in Italy, the incidence of gastric MALT lymphomas may be declining particularly in developed countries where the prevalence of H. pylori infection is decreasing [225].

Some evidence from case-series data has further indicated that infection with certain bacterial agents is associated with specific subtypes of NHL. Infection with the bacteria Campylobacter jejuni and Chlamydia psittaci, which can infect humans via contact with animal feces and contact with birds, respectively, and the vector borne agent Borrelia burgdorferi has been associated with rare MALT lymphomas, including immunoproliferative small intestinal disease, ocular adnexal lymphoma, and cutaneous MALT lymphoma, respectively [226]. However, these agents are only variably found in the respective lesions and the magnitude of the risks associated with these exposures are not well defined [226].

2.2. Obesity. Increasing attention has been given to the potential relationship between cancer risk and obesity, given that obesity is associated with chronic, low-grade inflammation, and specific immune alterations including changes in cytokine profiles that may alter the immune response [227]. Moreover, the obesity-associated hormone leptin has been demonstrated to influence proinflammatory responses as well as have specific effects on helper T-lymphocyte function [227].

Some evidence has emerged suggesting that obesity or higher BMI may increase the risk of NHL, particularly for specific histological subtypes including DLBCL. DLBCL was positively associated with severe obesity (OR 1.80, 95\% CI 1.24-2.62) in a pooled InterLymph analysis that included 10,453 cases and 16,507 controls (Table 1), and recent pooled and meta-analyses have indicated a marginally elevated association for NHL and DLBCL with either obesity $(\mathrm{BMI} \geq 30)$ or per $5 \mathrm{~kg} / \mathrm{m}^{2}$ increase in BMI [28, 228, 229]. Prospective studies have generally supported these findings, with evidence that higher BMI at both younger ages and during midlife may be relevant to NHL risk [20, 230, 231].

2.3. Autoimmune Disease and Allergy. Several epidemiologic studies that have examined the role of autoimmunity have reported an increased risk of NHL for specific conditions, particularly for Sjogren's syndrome [232-240], systemic lupus erythematosus $[232-234,241,242]$, celiac disease [234, 243-245], and rheumatoid arthritis [239, 246, 247]. Moreover, positive associations with overall NHL or for specific subtypes have been reported less consistently for other inflammatory disorders including psoriasis, inflammatory bowel disease particularly for Crohn's disease, and Hashimoto's thyroiditis as reviewed elsewhere [248].

There is also evidence suggesting associations with specific NHL subtypes for some of these disorders, including enteropathy-associated T-cell lymphoma and celiac disease [249], marginal zone lymphoma of the parotid gland and Sjogren's syndrome [233], and MALT lymphoma of the thyroid gland associated with Hashimoto's thyroiditis from case-series data [250]. Whereas case reports and some observational studies suggest that treatment with antirheumatic drugs and some anti-inflammatory treatments, such as tumor necrosis factor antagonists, increase NHL risk, these associations are inconclusive given possible confounding by indication and the conflicting findings across studies [248]. Given the low prevalence of some autoimmune and atopic conditions in the general population, and the possibility that some but not all NHL subtypes may be associated with these conditions, large pooling studies may offer important insight into these associations.

Findings from InterLymph in a study of 12,984 cases and 16,441 controls have suggested an increased risk of overall NHL (OR 6.56, 95\% CI 3.10-13.9) and specifically DLBCL and FL for patients with Sjogren's syndrome as well as an association with overall NHL (OR 2.69, 95\% CI 1.684.30), DLBCL, and marginal zone lymphoma for systemic lupus erythematosus [233]. This same study reported positive findings for T-cell lymphoma associated with celiac disease and psoriasis. Conversely, a pooled InterLymph study including 13,535 cases and 16,388 controls has reported a modest reduction in risk of NHL for a history of any allergy (OR 0.80, 95\% CI 0.68-0.94), particularly for Bcell subtypes, and two population-based case-control studies in Australia and the United States found a reduced risk of NHL associated with some allergic conditions, including hay fever, eczema, and/or food allergies specifically [251253]. Findings from an EpiLymph case-control study with 2,480 cases of lymphoma and 2,540 controls have similarly suggested a reduced risk of overall NHL and specifically BNHL for history of food allergies [254]. These collective findings are suggestive of a reduced risk of NHL associated with a Th2-dominated immune response, whereas chronic immune stimulation may increase risk.

2.4. Family Size. The relationship between NHL and atopy and viral infections may substantiate the "hygiene hypothesis," suggesting that delayed infection during childhood 
may contribute to an over-activation of the Th2 mediated immune response, in turn promoting the development of atopy. Some epidemiological evidence suggests that children with fewer siblings or delayed first infection may have a reduced risk of NHL, and that household crowding and having a greater number of siblings increases risk, but not all studies have observed this association [209, 252, 255257]. Further, about a twofold increased risk of DLBCL specifically was found to be associated with being the last born in those with at least one sibling [1]. However, a large InterLymph study with 13,535 NHL cases and 16,427 controls found limited evidence for an association with overall NHL for either birth order or sibship size, though positive associations were reported for some subtypes [258]. Number of older siblings was also not associated with NHL in a large population based study using data from the Swedish-Family Cancer Database [259].

2.5. Reproductive Factors. Several epidemiological studies have evaluated the association between reproductive factors and NHL, including for age at menarche, age at first birth, and use of oral contraceptives (OCs) and/or hormone replacement therapy (HRT). Collectively, these studies have not been suggestive of a major role of reproductive factors in NHL risk with respect to age at menopause [260-263] or menarche [260, 262, 264-266], although an elevated risk of NHL and particularly for the diffuse subtype was reported for age at menarche $\geq 15$ years in a case-control study of Connecticut women [261]. However, other reproductive factors have been inconsistently associated with overall NHL or particular subtypes. Findings from an EpiLymph casecontrol study which included 847 cases of B-or T-cell neoplasms and 1,141 frequency-matched controls suggested a reduced risk of both mature $\mathrm{B}-(\mathrm{OR}$ per 1 child increase $=$ 0.87, 95\% CI 0.81-0.93) and T-cell (OR per 1 child increase $=0.71,95 \%$ CI $0.54-0.94$ ) lymphoma associated with increasing parity, including for CLL/SLL and DLBCL [267]. A similar significant NHL risk reduction or for the diffuse subtype has been observed for a higher number of pregnancies in two population-based case-control studies conducted in Connecticut and San Francisco [261, 265], while the association has been less consistent in cohort studies $[260,268,269]$. There is additionally limited evidence suggesting an inverse association with NHL for either age at first full-term pregnancy or for breastfeeding [260, 269], but other studies have not observed these associations [261, 268, 270].

Exposure to exogenous hormones through the use of OCs and HRT have also been investigated in relation to overall NHL risk and the findings have been equivocal, with generally either null findings $[261,262,266]$ or an associated protective effect for NHL associated with OC use or menopausal hormone therapy $[263,265,270]$. Recent examination of contraceptive use in the large EpiLymph case-control study found no significant association with Bcell neoplasms for ever use of contraceptives, but women who used contraceptives for $<5$ years had significantly elevated risks of DLBCL and FL compared with never users
[267]. Most recently, reproductive factors and hormonal contraception use have been evaluated by InterLymph in a study of 4,263 NHL cases and 5,971 controls [266]. Whereas there was no evidence for an association for overall NHL or DLBCL with reproductive factors or hormonal contraception use, a decreased risk of FL was observed for increasing number of pregnancies ( $\mathrm{OR}=0.88,95 \%$ CI 0.81 0.96 ), while ever use of hormonal contraception increased the risk of FL. The increased risk was particularly apparent in those who used hormonal contraceptives $\leq 5$ years and who were $>22$ years of age at first use.

2.6. Blood Transfusion and Organ Transplantation. Three cohort studies have suggested an increased risk of NHL, particularly of low grade, associated with a previous history of having received a blood transfusion [271-273]; however, most case-control studies with the exception of one conducted in Sweden have reported no increase in risk [274-278]. In the Swedish case-control study, an overall increased risk of NHL was associated with having had a blood transfusion, particularly in the 6-15-year period before diagnosis (OR 2.83, 95\% CI 1.60-4.99) with the highest risks observed for nodal B-CLL and high-grade extranodal lymphomas [279].

Recently, the first meta-analysis of this association, including 14 studies, found about a $20 \%$ increase in risk of NHL overall and CLL/SLL specifically for blood transfusions, though the overall association was limited to the included cohort studies [280]. Blood transfusions result in a decline in cell-mediated immunity, but a number of methodological challenges in these studies including potential biases and limited assessment of NHL subtypes have precluded firm conclusions regarding this relationship $[281,282]$.

Previous organ transplantation, including heart, kidney, and liver transplants, is associated with a subsequent increased risk of NHL and/or lymphoproliferative disease, with the highest risks generally observed during the first year aftertransplant [283-288]. Risks arise primarily due to the use of post-transplant immunosuppressive medications, and evidence suggests that risks differ according to the specific organ transplanted $[283,287,288]$.

2.7. Medications. There is some evidence indicating an association with NHL for use of medications including for statins, NSAIDs, antibiotics, and antidepressants. The strongest evidence for an association with statin use has come from an EpiLymph case-control study which included 2,362 cases of B-and T-cell lymphoma and 2,206 controls and collected information on medication use through personal interviews [289]. Ever use of statins was associated with about a $40 \%$ reduced risk of lymphoma (OR $0.61,95 \%$ CI $0.45-0.84$ ), but there was limited evidence of a dose-response effect according to duration of use. A reduced risk of NHL for ever use of statins has similarly been reported in a population based case-control study in Connecticut [290], in a cohort of HIV-positive individuals [291], as well as in other cohorts [292], but not in all studies [293]. Experimental studies have suggested that statins may possess anti-inflammatory 
properties and evidence suggests that these agents may inhibit tumor cell growth and metastases [294].

Some studies have indicated that greater use of NSAIDs $[295,296]$ or antibiotics [297-299] may result in an increased risk of NHL, but it is generally unclear as to what extent the underlying medical conditions for which these medications were taken may have contributed to the observed risk. Notably, a meta-analysis of nine epidemiologic studies which included a total 5,794 NHL cases and 34,707 controls for the NSAID analysis found no elevated risk of NHL for NSAID use or for use of corticosteroids [300], but this analysis did not consider duration of exposure or the possibility of an association in distinct subgroups. Whereas previous studies have suggested an increased risk of NHL associated with NSAID use overall or for specific NSAID medications specifically in women [296, 301] or for longer duration of use $[296,299]$, there is conflicting evidence from two population-based case-control studies in the United States which did not observe a significantly elevated risk of NHL for NSAID use [302, 303].

The associations between antibiotic use and NHL risk have been examined in population-based case-control studies which have evaluated antibiotic use either through direct interviews or utilizing pharmacy databases $[298,299,304$, 305] as well as in a recent nationwide register-based cohort study in Denmark [297]. Greater use of antibiotics has been reported to increase NHL risk in two of these case-control studies, both of which utilized personal interviews [298, 299], but no increase in risk was observed for NHL; however, in two additional population-based case-controls studies one of which utilized pharmacy records for the antibiotic exposure assessment $[304,305]$. The cohort study which included the entire adult population of Denmark aged 15 or older and utilized a national prescription registry in addition to evaluating multiple NHL subtypes found a marginally elevated risk of overall NHL for ever use of antibiotics (RR 1.13 , 95\% CI 1.08-1.19), with the highest risk estimates reported for anaplastic large T-cell lymphoma, CLL/SLL, and mantle cell lymphoma [297]. Overall, a limitation in the assessment of these studies which have observed elevated associations is the potential for confounding by indication and exposure misclassification in studies that have relied on personal interviews.

Evidence for an association with NHL for use of antidepressants is currently limited, but results from a population-based cohort study in Denmark have indicated an elevated association for NHL for higher use categories of tricyclic antidepressants $[306,307]$. These studies have utilized pharmacy data for the exposure assessment but have provided limited assessment of subtype specific associations. Antidepressant use, including tricyclic antidepressants, was not significantly associated with NHL in a previous cohort of HIV-positive individuals or in a population-based casecontrol study in Canada which evaluated antidepressant use via self-administered questionnaires [308, 309].

2.8. Genetics. The observed increasing trend in NHL incidence is likely the result of environmental and/or lifestyle factors, but an important consideration is that genetic factors may modify associations between environmental risk factors and NHL, and this may contribute at least in part to the inconsistencies between studies. Indeed, studies have suggested that polymorphisms in Th1/Th2 pathway genes modify the association between BMI and NHL [310], that NHL risk associated with hair dye use is modified by variation in NAT1 and NAT2 genes [311], and that the relationship between organochlorine exposure and NHL is influenced by variants in IFNG and interleukin genes [312]. Similar examples of gene-environment interactions involving NHL risk have included fruit and vegetable intake (NOS1) [313], solvent exposure and metabolic genes [314], and smoking (NAT2) [315], suggesting the importance of considering genetic influences when evaluating NHL risk in relation to environmental and lifestyle factors. However, this evidence for gene-environment interactions in relation to NHL risk is based on the results of single studies with limited power to evaluate the associations, particularly for specific NHL subtypes.

Numerous candidate gene studies of overall NHL and for specific NHL subtypes have been conducted, and these findings have been extensively reviewed elsewhere [316]. Overall, genetic variation in several pathways have been implicated in NHL risk, including in one-carbon metabolism, cytokine, innate immunity, oxidative stress, and apoptotic and DNA repair pathways as well as in the HLA region [316]. Pooled InterLymph analyses in particular have suggested an elevated risk of NHL and particularly DLBCL associated with the TNF-308G $\rightarrow$ A and IL10-3575T $\rightarrow$ A variants [317] and with the LTA $252 \mathrm{~A} \rightarrow \mathrm{G} / \mathrm{TNF}-308 \mathrm{G} \rightarrow \mathrm{A}$ haplotype for DLBCL [318]. Over the past several years, ongoing genomewide association studies (GWAS) have been conducted for common NHL subtypes and the results of these studies have provided additional insight into the genetic basis of this disease [319-323]. Specifically, GWAS of FL have suggested a protective effect associated with rs6457327 on 6p21.33, which contains the HLA region and is located near psoriasis susceptibility region 1, and associations with rs10484561 and rs7755224 on 6 p21.32 [320, 321]. Recently, a third GWAS of FL identified an additional variant on 6p21.32, rs2647012, associated with a reduced risk of FL and located 962 bp away from rs10484561, which was also associated with DLBCL [319]. These findings suggest the potential importance of the HLA class II region in NHL susceptibility and for FL in particular.

GWAS of CLL/SLL have identified several risk loci for this subtype, with the strongest associations observed for rs872071 on 6p25.3 which encompasses IRF4, and rs2456449 on 8q24.21 [322, 323]. IRF4 regulates lymphoid development and proliferation, while the $8 \mathrm{q} 24$ genomic region has been implicated as a susceptibility locus for multiple cancer types [322, 323]. The 6p21.3 locus, which harbors HLA class II genes, has also emerged as a potential susceptibility locus associated with familial CLL [324]. Notably, several of the variants that have emerged from the GWAS of CLL/SLL have been subsequently validated in other case-control studies, including for variants at $15 \mathrm{q} 25.2$ (rs783540), 18q21.1 (rs1036935), 2q37.1 (rs13397985), 
6p25.3 (rs872071), 11q24.1 (rs735665), 15q23 (rs7176508), and $19 \mathrm{q} 13.32$ (rs11083846) $[325,326]$. Ongoing and future GWAS should clarify the many putative associations that have been previously reported in candidate gene studies.

\section{Conclusion}

Extensive epidemiological investigation has been devoted to postulated lifestyle and environmental risk factors that may explain the rise in NHL incidence over the past several decades. While some etiologic clues have emerged, patterns of NHL incidence remain largely unexplained and cannot be solely attributed to changes in rates of HIV infection. Whereas severe immunosuppression, resulting from immunodeficiency syndromes and postorgan transplantation, and some infectious agents are established risk factors for NHL or specific subtypes, the contribution of most environmental exposures and lifestyle or dietary components remain unclear.

Specifically, positive associations with NHL have been reported for the use of hair dye before 1980, diets high in fat and some dairy products, higher BMI, smoking for FL, as well as exposure to certain solvents and chemicals. However, the inconsistency in some of these associations across studies precludes their consideration as established NHL risk factors, and the associated risk estimates have generally been only marginally elevated. Moving forward, increased emphasis on potential etiologic differences for NHL subtypes, further examination of underlying mechanisms to establish biologic plausibility, exposure assessments which consider multiple metrics of exposure, and further consideration of potential gene-environment interactions will be critical in clarifying the role of putative environmental and lifestyle risk factors for NHL.

\section{References}

[1] L. M. Morton, S. S. Wang, W. Cozen et al., "Etiologic heterogeneity among non-Hodgkin lymphoma subtypes," Blood, vol. 112, no. 13, pp. 5150-5160, 2008.

[2] J. S. H. Ferlay, F. Bray, D. Forman, C. Mathers, and D. M. Parkin, GLOBOCAN 2008, Cancer Incidence and Mortality Worldwide, IARC CancerBase No. 10 [Internet]. Lyon, France, International Agency for Research on Cancer, 2010, http://globocan.iarc.fr/.

[3] N. Howlander, A. M. Noone, M. Krapcho et al., "SEER Cancer Statistics Review, 1975-2009," National Cancer Institute, Bethesda, Md, USA, based on November 2011 SEER data submission, posted to the SEER web site, 2012, http://seer.cancer.gov/csr/1975_2009_pops09/.

[4] C. A. Clarke and S. L. Glaser, "Changing incidence of nonHodgkin lymphomas in the United States," Cancer, vol. 94, no. 7, pp. 2015-2023, 2002.

[5] P. H. Levine and R. Hoover, "The emerging epidemic of nonHodgkin's lymphoma: current knowledge regarding etiological factors," Cancer Epidemiology, Biomarkers \& Prevention, vol. 1, no. 6, pp. 515-517, 1992.

[6] P. Boffetta, B. Armstrong, M. Linet, C. Kasten, W. Cozen, and P. Hartge, "Consortia in cancer epidemiology: lessons from InterLymph," Cancer Epidemiology Biomarkers and Prevention, vol. 16, no. 2, pp. 197-199, 2007.

[7] L. M. Morton, J. J. Turner, J. R. Cerhan et al., "Proposed classification of lymphoid neoplasms for epidemiologic research from the Pathology Working Group of the International Lymphoma Epidemiology Consortium (InterLymph)," Blood, vol. 110, no. 2, pp. 695-708, 2007.

[8] R. A. Nelson, A. M. Levine, G. Marks, and L. Bernstein, "Alcohol, tobacco and recreational drug use and the risk of non-Hodgkin's lymphoma," British Journal of Cancer, vol. 76, no. 11, pp. 1532-1537, 1997.

[9] E. V. Willett, A. G. Smith, G. J. Dovey, G. J. Morgan, J. Parker, and E. Roman, "Tobacco and alcohol consumption and the risk of non-Hodgkin lymphoma," Cancer Causes and Control, vol. 15, no. 8, pp. 771-780, 2004.

[10] R. Casey, K. Piazzon-Fevre, N. Raverdy et al., "Casecontrol study of lymphoid neoplasm in three French areas: description, alcohol and tobacco consumption," European Journal of Cancer Prevention, vol. 16, no. 2, pp. 142-150, 2007.

[11] A. Nieters, S. Rohrmann, N. Becker et al., "Smoking and lymphoma risk in the European prospective investigation into cancer and nutrition," American Journal of Epidemiology, vol. 167, no. 9, pp. 1081-1089, 2008.

[12] P. Fernberg, A. Odenbro, R. Bellocco, P. Boffetta, Y. Pawitan Y, and J. Adami, "Tobacco use, body mass index and the risk of malignant lymphomas-a nationwide cohort study in Sweden," International Journal of Cancer, vol. 118, no. 9, pp. 2298-2302, 2006.

[13] C. Schollkopf, K. E. Smedby, H. Hjalgrim et al., "Cigarette smoking and risk of non-Hodgkin's lymphoma-a population-based case-control study," Cancer Epidemiology Biomarkers and Prevention, vol. 14, no. 7, pp. 1791-1796, 2005.

[14] L. M. Morton, T. R. Holford, B. Leaderer et al., "Cigarette smoking and risk of non-Hodgkin lymphoma subtypes among women," British Journal of Cancer, vol. 89, no. 11, pp. 2087-2092, 2003.

[15] L. M. Morton, P. Hartge, T. R. Holford et al., "Cigarette smoking and risk of non-Hodgkin lymphoma: a pooled analysis from the International Lymphoma Epidemiology Consortium (InterLymph)," Cancer Epidemiology Biomarkers and Prevention, vol. 14, no. 4, pp. 925-933, 2005.

[16] A. S. Parker, J. R. Cerhan, F. Dick et al., "Smoking and risk of non-Hodgkin lymphoma subtypes in a cohort of older women," Leukemia and Lymphoma, vol. 37, no. 3-4, pp. 341349, 2000.

[17] H. Besson, P. Brennan, N. Becker et al., "Tobacco smoking, alcohol drinking and non-Hodgkin's lymphoma: a European multicenter case-control study (Epilymph)," International Journal of Cancer, vol. 119, no. 4, pp. 901-908, 2006.

[18] L. J. Herrinton and G. D. Friedman, "Cigarette smoking and risk of non-Hodgkin's lymphoma subtypes," Cancer Epidemiology Biomarkers and Prevention, vol. 7, no. 1, pp. 2528, 1998.

[19] Y. Lu, S. S. Wang et al., "Cigarette smoking, passive smoking, and non-Hodgkin lymphoma risk: evidence from the California Teachers Study," American Journal of Epidemiology, vol. 174, pp. 563-573, 2011.

[20] J. D. Troy, P. Hartge, J. L. Weissfeld et al., "Associations between anthropometry, cigarette smoking, alcohol consumption, and non-Hodgkin lymphoma in the prostate, lung, colorectal, and ovarian cancer screening trial," 
American Journal of Epidemiology, vol. 171, no. 12, pp. 12701281, 2010.

[21] U. Lim, L. M. Morton, A. F. Subar et al., "Alcohol, smoking, and body size in relation to incident Hodgkin's and nonHodgkin's lymphoma risk," American Journal of Epidemiology, vol. 166, no. 6, pp. 697-708, 2007.

[22] L. M. Morton, T. Zheng, T. R. Holford et al., "Alcohol consumption and risk of non-Hodgkin lymphoma: a pooled analysis," Lancet Oncology, vol. 6, no. 7, pp. 469-476, 2005.

[23] A. Kricker, B. K. Armstrong, A. M. Hughes et al., "Personal sun exposure and risk of non Hodgkin lymphoma: a pooled analysis from the Interlymph Consortium," International Journal of Cancer, vol. 122, no. 1, pp. 144-154, 2008.

[24] P. Boffetta, O. van der Hel, A. Kricker et al., "Exposure to ultraviolet radiation and risk of malignant lymphoma and multiple myeloma- a multicentre European case-control study," International Journal of Epidemiology, vol. 37, no. 5, pp. 1080-1094, 2008.

[25] P. Cocco, A. T’Mannetje, D. Fadda et al., "Occupational exposure to solvents and risk of lymphoma subtypes: results from the Epilymph case-control study," Occupational and Environmental Medicine, vol. 67, no. 5, pp. 341-347, 2010.

[26] Y. Zhang, S. D. Sanjose, P. M. Bracci et al., "Personal use of hair dye and the risk of certain subtypes of non-Hodgkin lymphoma," American Journal of Epidemiology, vol. 167, no. 11, pp. 1321-1331, 2008.

[27] S. de Sanjosé, Y. Benavente, A. Nieters et al., "Association between personal use of hair dyes and lymphoid neoplasms in Europe," American Journal of Epidemiology, vol. 164, no. 1, pp. 47-55, 2006.

[28] E. V. Willett, L. M. Morton, P. Hartge et al., "NonHodgkin lymphoma and obesity: a pooled analysis from the InterLymph consortium," International Journal of Cancer, vol. 122, no. 9, pp. 2062-2070, 2008.

[29] G. Ott and A. Rosenwald, "Molecular pathogenesis of follicular lymphoma," Haematologica, vol. 93, no. 12, pp. 1773-1776, 2008.

[30] F. Schüler, C. Hirt, and G. Dölken, "Chromosomal translocation $\mathrm{t}(14 ; 18)$ in healthy individuals," Seminars in Cancer Biology, vol. 13, no. 3, pp. 203-209, 2003.

[31] R. Kalra, S. P. Singh, S. M. Savage, G. L. Finch, and M. L. Sopori, "Effects of cigarette smoke on immune response: chronic exposure to cigarette smoke impairs antigenmediated signaling in T cells and depletes IP3-sensitive $\mathrm{Ca}^{2+}$ stores," Journal of Pharmacology and Experimental Therapeutics, vol. 293, no. 1, pp. 166-171, 2000.

[32] A. Monnereau, L. Orsi, X. Troussard et al., "Cigarette smoking, alcohol drinking, and risk of lymphoid neoplasms: results of a French case-control study," Cancer Causes and Control, vol. 19, no. 10, pp. 1147-1160, 2008.

[33] B. C. H. Chiu, J. R. Cerhan, S. M. Gapstur et al., "Alcohol consumption and non-Hodgkin lymphoma in a cohort of older women," British Journal of Cancer, vol. 80, no. 9, pp. 1476-1482, 1999.

[34] J. Kanda, K. Matsuo, M. Inoue et al., "Association of alcohol intake with the risk of malignant lymphoma and plasma cell myeloma in Japanese: a population-based cohort study (Japan Public Health Center-based prospective study)," Cancer Epidemiology Biomarkers and Prevention, vol. 19, no. 2, pp. 429-434, 2010.

[35] E. A. Holly, C. Lele, P. M. Bracci, and M. S. McGrath, "Case-control study of non-Hodgkin's lymphoma among women and heterosexual men in the San Francisco Bay Area,
California," American Journal of Epidemiology, vol. 150, no. 4, pp. 375-389, 1999.

[36] E. De Stefani, L. Fierro, E. Barrios, and A. Ronco, "Tobacco, alcohol, diet and risk of non-Hodgkin's lymphoma: a casecontrol study in Uruguay," Leukemia Research, vol. 22, no. 5, pp. 445-452, 1998.

[37] D. S. Freedman, P. E. Tolbert, R. Coates, E. A. Brann, and C. R. Kjeldsberg, "Relation of cigarette smoking to nonHodgkin's lymphoma among middle-aged men," American Journal of Epidemiology, vol. 148, no. 9, pp. 833-841, 1998.

[38] O. Wong, F. Harris, Y. Wang, and H. Fu, "A hospital-based case-control study of non-Hodgkin lymphoid neoplasms in Shanghai: analysis of personal characteristics, lifestyle, and environmental risk factors by subtypes of the WHO classification," Journal of Occupational and Environmental Medicine, vol. 52, no. 1, pp. 39-53, 2010.

[39] A. Tavani, S. Gallus, C. La Vecchia, and S. Franceschi, "Alcohol drinking and risk of non-Hodgkin's lymphoma," European Journal of Clinical Nutrition, vol. 55, no. 10, pp. 824-826, 2001.

[40] E. T. Chang, K. E. Smedby, S. M. Zhang et al., "Alcohol intake and risk of non-Hodgkin lymphoma in men and women," Cancer Causes and Control, vol. 15, no. 10, pp. 1067-1076, 2004.

[41] B. C. H. Chiu, D. D. Weisenburger, K. P. Cantor et al., "Alcohol consumption, family history of hematolymphoproliferative cancer, and the risk of non-Hodgkin's lymphoma in men," Annals of Epidemiology, vol. 12, no. 5, pp. 309-315, 2002.

[42] E. T. Chang, C. A. Clarke, A. J. Canchola et al., "Alcohol consumption over time and risk of lymphoid malignancies in the California Teachers Study cohort," American Journal of Epidemiology, vol. 172, no. 12, pp. 1373-1383, 2010.

[43] I. Tramacere, C. Pelucchi, M. Bonifazi et al., "Alcohol drinking and non-Hodgkin lymphoma risk: a systematic review and a meta-analysis," Annals of Oncology. In press.

[44] L. M. Morton, T. R. Holford, B. Leaderer et al., "Alcohol use and risk of non-Hodgkin's lymphoma among Connecticut women (United States)," Cancer Causes and Control, vol. 14, no. 7, pp. 687-694, 2003.

[45] N. C. Briggs, R. S. Levine, L. D. Bobo, W. P. Haliburton, E. A. Brann, and C. H. Hennekens, "Wine drinking and risk of non-Hodgkin's lymphoma among men in the United States: a population-based case-control study," American Journal of Epidemiology, vol. 156, no. 5, pp. 454-462, 2002.

[46] M. Jang, L. Cai, G. O. Udeani et al., "Cancer chemopreventive activity of resveratrol, a natural product derived from grapes," Science, vol. 275, no. 5297, pp. 218-220, 1997.

[47] P. Bruno, L. Ghisolfi, M. Priulla, A. Nicolin, and A. Bertelli, "Wine and tumors: study of resveratrol," Drugs under Experimental and Clinical Research, vol. 29, no. 5-6, pp. 257261, 2003.

[48] L. E. Díaz, A. Montero, M. González-Gross, A. I. Vallejo, J. Romeo, and A. Marcos, "Influence of alcohol consumption on immunological status: a review," European Journal of Clinical Nutrition, vol. 56, supplement 3, pp. S50-S53, 2002.

[49] Y. Zhang, T. R. Holford, B. Leaderer et al., "Hair-coloring product use and risk of non-Hodgkin's lymphoma: a population-based case-control study in Connecticut," American Journal of Epidemiology, vol. 159, no. 2, pp. 148-154, 2004.

[50] Y. Benavente, N. Garcia, E. Domingo-Domenech et al., "Regular use of hair dyes and risk of lymphoma in Spain," 
International Journal of Epidemiology, vol. 34, no. 5, pp. 1118 1122, 2005.

[51] F. Grodstein, C. H. Hennekens, G. A. Colditz, D. J. Hunter, and M. J. Stampfer, "A prospective study of permanent hair dye use and hematopoietic cancer," Journal of the National Cancer Institute, vol. 86, no. 19, pp. 1466-1470, 1994.

[52] J. B. Mendelsohn, Q. Z. Li, B. T. Ji et al., "Personal use of hair dye and cancer risk in a prospective cohort of Chinese women," Cancer Science, vol. 100, no. 6, pp. 1088-1091, 2009.

[53] B. N. Ames, H. O. Kammen, and E. Yamasaki, "Hair dyes are mutagenic: identification of a variety of mutagenic ingredients," Proceedings of the National Academy of Sciences of the United States of America, vol. 72, no. 6, pp. 2423-2427, 1975.

[54] J. Adami, M. Frisch, J. Yuen, B. Glimelius, and M. Melbye, "Evidence of an association between non-Hodgkin's lymphoma and skin cancer," British Medical Journal, vol. 310, no. 6993, pp. 1491-1495, 1995.

[55] D. B. McKenna, D. Stockton, D. H. Brewster, and V. R. Doherty, "Evidence for an association between cutaneous malignant melanoma and lymphoid malignancy: a population-based retrospective cohort study in Scotland," British Journal of Cancer, vol. 88, no. 1, pp. 74-78, 2003.

[56] W. B. Goggins, D. M. Finkelstein, and H. Tsao, "Evidence for an association between cutaneous melanoma and nonHodgkin lymphoma," Cancer, vol. 91, pp. 874-880, 2001.

[57] P. Hall, I. Rosendahl, A. Mattsson, and S. Einhorn, "NonHodgkin's lymphoma and skin malignancies-shared etiology?" International Journal of Cancer, vol. 62, no. 5, pp. 519522, 1995.

[58] K. K. Hanneman, K. D. Cooper, and E. D. Baron, "Ultraviolet immunosuppression: mechanisms and consequences," Dermatologic Clinics, vol. 24, no. 1, pp. 19-25, 2006.

[59] M. S. Santos, S. N. Meydani, L. Leka et al., "Natural killer cell activity in elderly men is enhanced by $\beta$-carotene supplementation," American Journal of Clinical Nutrition, vol. 64, no. 5, pp. 772-777, 1996.

[60] H. K. Biesalski, C. Hemmes, W. Hopfenmuller, C. Schmid, and H. P. M. Gollnick, "Effects of controlled exposure of sunlight on plasma and skin levels of $\beta$-carotene," Free Radical Research, vol. 24, no. 3, pp. 215-224, 1996.

[61] G. Bentham, "Association between incidence of nonHodgkin's lymphoma and solar ultraviolet radiation in England and Wales," British Medical Journal, vol. 312, no. 7039, pp. 1128-1131, 1996.

[62] A. J. McMichael and G. G. Giles, "Have increases in solar ultraviolet exposure contributed to the rise in incidence of non-Hodgkin's lymphoma?" British Journal of Cancer, vol. 73, no. 7, pp. 945-950, 1996.

[63] S. Hu, F. Ma, F. Collado-Mesa, and R. S. Kirsner, "Ultraviolet Radiation and Incidence of non-Hodgkin's Lymphoma among Hispanics in the United States," Cancer Epidemiology Biomarkers and Prevention, vol. 13, no. 1, pp. 59-64, 2004.

[64] P. Hartge, S. S. Devesa, D. Grauman, T. R. Fears, and J. F. Fraumeni, "Non-Hodgkin's lymphoma and sunlight," Journal of the National Cancer Institute, vol. 88, no. 5, pp. 298-300, 1996.

[65] Y. Zhang, T. R. Holford, B. Leaderer et al., "Ultraviolet radiation exposure and risk of non-Hodgkin's lymphoma," American Journal of Epidemiology, vol. 165, no. 11, pp. 12551264, 2007.

[66] J. Adami, G. Gridley et al., "Sunlight and non-Hodgkin's lymphoma: a population-based cohort study in Sweden," International Journal of Cancer, vol. 80, pp. 641-645, 1999.
[67] K. A. Bertrand, E. T. Chang, G. A. Abel et al., "Sunlight exposure, vitamin $\mathrm{D}$, and risk of non-Hodgkin lymphoma in the Nurses' Health Study," Cancer Causes and Control, vol. 22, pp. 1731-1741, 2011.

[68] K. E. Smedby, H. Hjalgrim, M. Melbye et al., "Ultraviolet radiation exposure and risk of malignant lymphomas," Journal of the National Cancer Institute, vol. 97, no. 3, pp. 199-209, 2005.

[69] L. K. Soni, L. Hou, S. M. Gapstur, A. M. Evens, D. D. Weisenburger, and B. C. H. Chiu, "Sun exposure and non-Hodgkin lymphoma: a population-based, case-control study," European Journal of Cancer, vol. 43, no. 16, pp. 23882395, 2007.

[70] A. M. Hughes, B. K. Armstrong, C. M. Vajdic et al., "Sun exposure may protect against non-Hodgkin lymphoma: a case-control study," International Journal of Cancer, vol. 112, no. 5, pp. 865-871, 2004.

[71] T. Weihkopf, N. Becker, A. Nieters et al., "Sun exposure and malignant lymphoma: a population-based case-control study in Germany," International Journal of Cancer, vol. 120, no. 11, pp. 2445-2451, 2007.

[72] J. L. Kelly, J. W. Friedberg, L. M. Calvi, E. van Wijngaarden, and S. G. Fisher, "A case-control study of ultraviolet radiation exposure, vitamin D, and lymphoma risk in adults," Cancer Causes and Control, vol. 21, no. 8, pp. 1265-1275, 2010.

[73] E. T. Petridou, S. K. Dikalioti, A. Skalkidou, E. Andrie, N. Dessypris, and D. Trichopoulos, "Sun exposure, birth weight, and childhood lymphomas: a case control study in Greece," Cancer Causes and Control, vol. 18, no. 9, pp. 1031-1037, 2007.

[74] E. T. Chang, A. J. Canchola, M. Cockburn et al., "Adulthood residential ultraviolet radiation, sun sensitivity, dietary vitamin D, and risk of lymphoid malignancies in the California Teachers Study,” Blood, vol. 118, no. 6, pp. 1591-1599, 2011.

[75] B. K. Armstrong and A. Kricker, "Sun exposure and nonHodgkin lymphoma," Cancer Epidemiology Biomarkers and Prevention, vol. 16, no. 3, pp. 396-400, 2007.

[76] M. P. Purdue, D. M. Freedman, S. M. Gapstur et al., "Circulating 25-Hydroxyvitamin D and risk of non-Hodgkin lymphoma: cohort Consortium Vitamin D Pooling Project of Rarer Cancers," American Journal of Epidemiology, vol. 172, no. 1, pp. 58-69, 2010.

[77] E. Erber, G. Maskarinec, U. Lim, and L. N. Kolonel, "Dietary vitamin D and risk of non-Hodgkin lymphoma: the multiethnic cohort," British Journal of Nutrition, vol. 103, no. 4, pp. 581-584, 2010.

[78] E. T. Chang, A. J. Canchola, M. Cockburn et al., "Adulthood residential ultraviolet radiation, sun sensitivity, dietary vitamin D, and risk of lymphoid malignancies in the California Teachers Study," Blood, vol. 118, pp. 1591-1599, 2011.

[79] S. E. Ullrich, "Does exposure to UV radiation induce a shift to a Th-2-like immune reaction?" Photochemistry and Photobiology, vol. 64, no. 2, pp. 254-258, 1996.

[80] A. J. Sigurdson, M. M. Doody, R. S. Rao et al., "Cancer incidence in the U.S. Radiologic technologists health study, 1983-1998," Cancer, vol. 97, no. 12, pp. 3080-3089, 2003.

[81] M. S. Linet, D. M. Freedman, A. K. Mohan et al., "Incidence of haematopoietic malignancies in US radiologic technologists," Occupational and Environmental Medicine, vol. 62, no. 12, pp. 861-867, 2005.

[82] A. K. Mohan, M. Hauptmann, D. M. Freedman et al., "Cancer and other causes of mortality among radiologic technologists in the United States," International Journal of Cancer, vol. 103, no. 2, pp. 259-267, 2003. 
[83] J. D. Boice Jr., M. M. Morin, A. G. Glass et al., "Diagnostic $\mathrm{x}$-ray procedures and risk of leukemia, lymphoma, and multiple myeloma," Journal of the American Medical Association, vol. 265, no. 10, pp. 1290-1294, 1991.

[84] F. Pettersson, M. Ryberg, and B. Maler, "Second primary cancer after treatment of invasive corcinoma of the uterine cervix, compared with those arising after treatment for in situ carcinomas. An effect of irradiation? A cancer registry study," Acta Obstetricia et Gynecologica Scandinavica, vol. 69, no. 2, pp. 161-174, 1990.

[85] P. D. Inskip, R. A. Kleinerman, M. Stovall et al., "Leukemia, lymphoma, and multiple myeloma after pelvic radiotherapy for benign disease," Radiation Research, vol. 135, no. 1, pp. 108-124, 1993.

[86] S. C. Darby, G. Reeves, T. Key, R. Doll, and M. Stovall, "Mortality in a cohort of women given X-ray therapy for metropathia haemorrhagica," International Journal of Cancer, vol. 56, no. 6, pp. 793-801, 1994.

[87] K. K. Karipidis, G. Benke, M. R. Sim et al., "Non-Hodgkin lymphoma and occupational radiation exposure assessed using local data," Occupational Medicine, vol. 59, no. 6, pp. 437-439, 2009.

[88] K. K. Karipidis, G. Benke, M. R. Sim et al., "Occupational exposure to ionizing and non-ionizing radiation and risk of non-Hodgkin lymphoma," International Archives of Occupational and Environmental Health, vol. 80, no. 8, pp. 663-670, 2007.

[89] C. R. Eheman, P. E. Tolbert, R. J. Coates, O. Devine, and J. W. Eley, "Case-control assessment of the association between non-Hodgkin's lymphoma and occupational radiation with doses assessed using a job exposure matrix," American Journal of Industrial Medicine, vol. 38, pp. 19-27, 2000.

[90] D. B. Richardson, C. Terschüren, and W. Hoffmann, "Occupational risk factors for non-Hodgkin's lymphoma: a population-based case-control study in Northern Germany," American Journal of Industrial Medicine, vol. 51, no. 4, pp. 258-268, 2008.

[91] Y. Shimizu, H. Kato, and W. J. Schull, "Studies of the mortality of A-bomb survivors: 9. Mortality, 1950-1985: part 2. Cancer mortality based on the recently revised doses (DS86)," Radiation Research, vol. 121, no. 2, pp. 120-141, 1990.

[92] Y. Shimizu, W. J. Schull, and H. Kato, "Cancer risk among atomic bomb survivors. The RERF life span study," Journal of the American Medical Association, vol. 264, no. 5, pp. 601604, 1990.

[93] D. B. Richardson, H. Sugiyama, S. Wing et al., "Positive associations between ionizing radiation and lymphoma mortality among men," American Journal of Epidemiology, vol. 169, no. 8, pp. 969-976, 2009.

[94] A. Berrington, S. C. Darby, H. A. Weiss, and R. Doll, "100 years of observation on British radiologists: mortality from cancer and other causes 1897-1997," British Journal of Radiology, vol. 74, no. 882, pp. 507-519, 2001.

[95] H. A. Weiss, S. C. Darby, and R. Doll, "Cancer mortality following x-ray treatment for ankylosing spondylitis," International Journal of Cancer, vol. 59, no. 3, pp. 327-338, 1994.

[96] B. Krishnan and G. J. Morgan, "Non-Hodgkin lymphoma secondary to cancer chemotherapy," Cancer Epidemiology Biomarkers and Prevention, vol. 16, no. 3, pp. 377-380, 2007.

[97] C. F. Skibola, "Obesity, diet and risk of non-Hodgkin lymphoma," Cancer Epidemiology Biomarkers and Prevention, vol. 16, no. 3, pp. 392-395, 2007.
[98] M. P. Purdue, D. G. Bassani, N. S. Klar et al., "Dietary factors and risk of non-Hodgkin lymphoma by histologic subtype: a case-control analysis," Cancer Epidemiology Biomarkers and Prevention, vol. 13, no. 10, pp. 1665-1676, 2004.

[99] B. C. H. Chiu, J. R. Cerhan, A. R. Folsom et al., "Diet and risk of non-Hodgkin lymphoma in older women," Journal of the American Medical Association, vol. 275, no. 17, pp. 1315$1321,1996$.

[100] S. Zhang, D. J. Hunter, B. A. Rosner et al., "Dietary fat and protein in relation to risk of non-Hodgkin's lymphoma among women," Journal of the National Cancer Institute, vol. 91, no. 20, pp. 1751-1758, 1999.

[101] T. Zheng, T. R. Holford, B. Leaderer et al., "Diet and nutrient intakes and risk of non-Hodgkin's lymphoma in connecticut women," American Journal of Epidemiology, vol. 159, no. 5, pp. 454-466, 2004.

[102] A. J. Cross, M. H. Ward, M. J. Schenk et al., "Meat and meatmutagen intake and risk of non-Hodgkin lymphoma: results from a NCI-SEER case-control study," Carcinogenesis, vol. 27, no. 2, pp. 293-297, 2006.

[103] D. A. Hughes, "Effects of dietary antioxidants on the immune function of middle-aged adults," Proceedings of the Nutrition Society, vol. 58, no. 1, pp. 79-84, 1999.

[104] J. Selhub, "Homocysteine metabolism," Annual Review of Nutrition, vol. 19, pp. 217-246, 1999.

[105] J. Polesel, R. Talamini, M. Montella et al., "Linoleic acid, vitamin $\mathrm{D}$ and other nutrient intakes in the risk of nonHodgkin lymphoma: an Italian case-control study," Annals of Oncology, vol. 17, no. 4, pp. 713-718, 2006.

[106] S. M. Zhang, D. J. Hunter, B. A. Rosner et al., "Intakes of fruits, vegetables, and related nutrients and the risk of nonHodgkin's lymphoma among women," Cancer Epidemiology Biomarkers and Prevention, vol. 9, no. 5, pp. 477-485, 2000.

[107] L. E. Kelemen, J. R. Cerhan, U. Lim et al., "Vegetables, fruit, and antioxidant-related nutrients and risk of non-Hodgkin lymphoma: a National Cancer Institute-Surveillance, Epidemiology, and End Results population-based case-control study," American Journal of Clinical Nutrition, vol. 83, no. 6, pp. 1401-1410, 2006.

[108] E. T. Chang, K. M. Bälter, A. Torrång et al., "Nutrient intake and risk of non-Hodgkin's lymphoma," American Journal of Epidemiology, vol. 164, no. 12, pp. 1222-1232, 2006.

[109] C. A. Thompson, T. M. Habermann, A. H. Wang et al., "Antioxidant intake from fruits, vegetables and other sources and risk of non-Hodgkin's lymphoma: the Iowa Women's Health Study," International Journal of Cancer, vol. 126, no. 4, pp. 992-1003, 2010.

[110] U. Lim, S. Weinstein, D. Albanes et al., "Dietary factors of one-carbon metabolism in relation to non-Hodgkin lymphoma and multiple myeloma in a cohort of male smokers," Cancer Epidemiology Biomarkers and Prevention, vol. 15, no. 6, pp. 1109-1114, 2006.

[111] U. Lim, M. Schenk, L. E. Kelemen et al., "Dietary determinants of one-carbon metabolism and the risk of nonHodgkin's lymphoma: NCI-SEER case-control study, 19982000," American Journal of Epidemiology, vol. 162, no. 10, pp. 953-964, 2005.

[112] S. Koutros, Y. Zhang, Y. Zhu et al., "Nutrients contributing to one-carbon metabolism and risk of non-Hodgkin lymphoma subtypes," American Journal of Epidemiology, vol. 167, pp. 287-294, 2008.

[113] J. Polesel, L. Dal Maso, C. La Vecchia et al., "Dietary folate, alcohol consumption, and risk of non-Hodgkin lymphoma," Nutrition and Cancer, vol. 57, no. 2, pp. 146-150, 2007. 
[114] U. Lim, S. S. Wang, P. Hartge et al., "Gene-nutrient interactions among determinants of folate and one-carbon metabolism on the risk of non-Hodgkin lymphoma: NCISEER case-control study," Blood, vol. 109, no. 7, pp. 30503059, 2007.

[115] H. Steinkellner, S. Rabot, C. Freywald et al., "Effects of cruciferous vegetables and their constituents on drug metabolizing enzymes involved in the bioactivation of DNA-reactive dietary carcinogens," Mutation Research-Fundamental and Molecular Mechanisms of Mutagenesis, vol. 480-481, pp. 285297, 2001.

[116] P. Boffetta and F. de Vocht, "Occupation and the risk of nonHodgkin lymphoma," Cancer Epidemiology Biomarkers and Prevention, vol. 16, no. 3, pp. 369-372, 2007.

[117] A. 'T Mannetje, E. Dryson, C. Walls et al., "High risk occupations for non-Hodgkin's lymphoma in New Zealand: casecontrol study," Occupational and Environmental Medicine, vol. 65, no. 5, pp. 354-363, 2008.

[118] T. Zheng, A. Blair, Y. Zhang, D. D. Weisenburger, and S. H. Zahm, "Occupation and risk of non-Hodgkin's lymphoma and chronic lymphocytic leukemia," Journal of Occupational and Environmental Medicine, vol. 44, no. 5, pp. 469-474, 2002.

[119] L. Fritschi, K. C. Johnson, E. V. Kliewer, and R. Fry, "Animalrelated occupations and the risk of leukemia, myeloma, and non-Hodgkin's lymphoma in Canada," Cancer Causes and Control, vol. 13, no. 6, pp. 563-571, 2002.

[120] C. P. Karunanayake, H. H. McDuffie, J. A. Dosman, J. J. Spinelli, and P. Pahwa, "Occupational exposures and non-Hodgkin's lymphoma: canadian case-control study," Environmental Health, vol. 7, article 44, 2008.

[121] L. Orsi, X. Troussard, A. Monnereau et al., "Occupation and lymphoid malignancies: results from a French case-control study," Journal of Occupational and Environmental Medicine, vol. 49, no. 12, pp. 1339-1350, 2007.

[122] J. Acquavella, G. Olsen, P. Cole et al., "Cancer among farmers: a meta-analysis," Annals of Epidemiology, vol. 8, no. 1, pp. 6474, 1998.

[123] S. A. Khuder, E. A. Schaub, and J. E. Keller-Byrne, "Metaanalyses of non-Hodgkin's lymphoma and farming," Scandinavian Journal of Work, Environment and Health, vol. 24, no. 4, pp. 255-261, 1998.

[124] J. E. Keller-Byrne, S. A. Khuder, E. A. Schaub, and O. McAfee, "A meta-analysis of non-Hodgkin's lymphoma among farmers in the central United States," American Journal of Industrial Medicine, vol. 31, pp. 442-444, 1997.

[125] M. A. Svec, M. H. Ward, M. Dosemeci, H. Checkoway, and A. J. De Roos, "Risk of lymphatic or haematopoietic cancer mortality with occupational exposure to animals or the public," Occupational and Environmental Medicine, vol. 62, no. 10, pp. 726-735, 2005.

[126] D. Amadori, O. Nanni, F. Falcini et al., "Chronic lymphocytic leukaemias and non-Hodgkin's lymphomas by histological type in farming-animal breeding workers: a population case-control study based on job titles," Occupational and Environmental Medicine, vol. 52, no. 6, pp. 374-379, 1995.

[127] L. Miligi, A. Seniori Costantini, P. Crosignani et al., "Occupational, environmental, and life-style factors associated with the risk of hematolymphopoietic malignancies in women," American Journal of Industrial Medicine, vol. 36, pp. 60-69, 1999.

[128] B. Mester, A. Nieters, E. Deeg, G. Elsner, N. Becker, and A. Seidler, "Occupation and malignant lymphoma: a population based case control study in Germany," Occupational and Environmental Medicine, vol. 63, no. 1, pp. 17-26, 2006.

[129] P. R. Band, N. D. Le, R. Fang, and R. Gallagher, "Identification of occupational cancer risks in British Columbia: a population-based case-control study of 769 cases of nonHodgkin's lymphoma analyzed by histopathology subtypes," Journal of Occupational and Environmental Medicine, vol. 46, no. 5, pp. 479-489, 2004.

[130] D. Neasham, A. Sifi, and K. R. Nielsen, "Occupation and risk of lymphoma: a multicentre prospective cohort study (EPIC)," Occupational and Environmental Medicine, vol. 68, no. 1, pp. 77-81, 2011.

[131] L. Tatham, P. Tolbert, and C. Kjeldsberg, "Occupational risk factors for subgroups of non-Hodgkin's lymphoma," Epidemiology, vol. 8, no. 5, pp. 551-558, 1997.

[132] T. Moore, P. Brennan, N. Becker et al., "Occupational exposure to meat and risk of lymphoma: a multicenter casecontrol study from Europe," International Journal of Cancer, vol. 121, no. 12, pp. 2761-2766, 2007.

[133] M. I. Cano and M. Pollán, "Non-Hodgkin's lymphomas and occupation in Sweden," International Archives of Осcupational and Environmental Health, vol. 74, no. 6, pp. 443-449, 2001.

[134] J. Ji and K. Hemminki, "Socioeconomic/occupational risk factors for lymphoproliferative diseases in Sweden," Annals of Epidemiology, vol. 16, no. 5, pp. 370-376, 2006.

[135] M. Schenk, M. P. Purdue, J. S. Colt et al., "Occupation/industry and risk of non-Hodgkin's lymphoma in the United States," Occupational and Environmental Medicine, vol. 66, pp. 23-31, 2009.

[136] A. S. Costantini, L. Miligi, D. Kriebel et al., "A multicenter case-control study in Italy on hematolymphopoietic neoplasms and occupation," Epidemiology, vol. 12, no. 1, pp. 7887, 2001.

[137] L. Orsi, A. Monnereau, B. Dananche et al., "Occupational exposure to organic solvents and lymphoid neoplasms in men: results of a French case-control study," Occupational and Environmental Medicine, vol. 67, no. 10, pp. 664-672, 2010.

[138] L. Fritschi, G. Benke, A. M. Hughes et al., "Risk of nonHodgkin lymphoma associated with occupational exposure to solvents, metals, organic dusts and PCBs (Australia)," Cancer Causes and Control, vol. 16, no. 5, pp. 599-607, 2005.

[139] M. A. V. Rêgo, C. S. Campos Sousa, M. Kato, A. Barreto de Carvalho, D. Loomis, and F. M. Carvalho, "Non-Hodgkin's lymphomas and organic solvents," Journal of Occupational and Environmental Medicine, vol. 44, no. 9, pp. 874-881, 2002.

[140] I. Kato, K. L. Koenig, H. Watanabe-Meserve et al., "Personal and occupational exposure to organic solvents and risk of non-Hodgkin's lymphoma (NHL) in women (United States)," Cancer Causes and Control, vol. 16, no. 10, pp. 12151224, 2005.

[141] E. Dryver, L. Brandt, T. Kauppinen, and H. Olsson, "Occupational exposures and non-Hodgkin's lymphoma in Southern Sweden," International Journal of Occupational and Environmental Health, vol. 10, no. 1, pp. 13-21, 2004.

[142] P. Vineis, L. Miligi, and A. S. Costantini, "Exposure to solvents and risk of non-Hodgkin lymphoma: clues on putative mechanisms," Cancer Epidemiology Biomarkers and Prevention, vol. 16, no. 3, pp. 381-384, 2007.

[143] R. Wang, Y. Zhang, Q. Lan et al., "Occupational exposure to solvents and risk of non-Hodgkin lymphoma in Connecticut 
women," American Journal of Epidemiology, vol. 169, no. 2, pp. 176-185, 2009.

[144] L. Miligi, A. S. Costantini, A. Benvenuti et al., "Occupational exposure to solvents and the risk of lymphomas," Epidemiology, vol. 17, no. 5, pp. 552-561, 2006.

[145] N. C. Briggs, R. S. Levine, H. I. Hall, O. Cosby, E. A. Brann, and C. H. Hennekens, "Occupational risk factors for selected cancers among African American and white men in the United States," American Journal of Public Health, vol. 93, no. 10, pp. 1748-1752, 2003.

[146] R. B. Hayes, S. N. Yin, M. Dosemeci et al., "Benzene and the dose-related incidence of hematologic neoplasms in China," Journal of the National Cancer Institute, vol. 89, no. 14, pp. 1065-1071, 1997.

[147] E. V. Kane and R. Newton, "Benzene and the risk of nonHodgkin lymphoma: a review and meta-analysis of the literature," Cancer Epidemiology, vol. 34, no. 1, pp. 7-12, 2010.

[148] M. T. Smith, R. M. Jones, and A. H. Smith, "Benzene exposure and risk of non-Hodgkin lymphoma," Cancer Epidemiology Biomarkers and Prevention, vol. 16, no. 3, pp. 385-391, 2007.

[149] D. D. Alexander and M. E. Wagner, "Benzene exposure and non-Hodgkin lymphoma: a meta-analysis of epidemiologic studies," Journal of Occupational and Environmental Medicine, vol. 52, no. 2, pp. 169-189, 2010.

[150] R. A. Rinsky, R. W. Hornung, S. R. Silver, and C. Y. Tseng, "Benzene exposure and hematopoietic mortality: a longterm epidemiologic risk assessment," American Journal of Industrial Medicine, vol. 42, no. 6, pp. 474-480, 2002.

[151] C. Steinmaus, A. H. Smith, R. M. Jones, and M. T. Smith, "Meta-analysis of benzene exposure and non-Hodgkin lymphoma: biases could mask an important association," Occupational and Environmental Medicine, vol. 65, no. 6, pp. 371-378, 2008.

[152] J. Vlaanderen, Q. Lan, H. Kromhout, N. Rothman, and R. Vermeulen, "Occupational benzene exposure and the risk of lymphoma subtypes: a meta-analysis of cohort studies incorporating three study quality dimensions," Environmental Health Perspectives, vol. 119, no. 2, pp. 159-167, 2011.

[153] C. S. Scott and W. A. Chiu, "Trichloroethylene cancer epidemiology: a consideration of select issues," Environmental Health Perspectives, vol. 114, no. 9, pp. 1471-1478, 2006.

[154] O. Raaschou-Nielsen, J. Hansen, J. K. McLaughlin et al., "Cancer risk among workers at danish companies using trichloroethylene: a Cohort Study," American Journal of Epidemiology, vol. 158, no. 12, pp. 1182-1192, 2003.

[155] J. Hansen, O. Raaschou-Nielsen, J. M. Christensen et al., "Cancer incidence among danish workers exposed to trichloroethylene," Journal of Occupational and Environmental Medicine, vol. 43, no. 2, pp. 133-139, 2001.

[156] A. Blair, P. Hartge, P. A. Stewart, M. McAdams, and J. Lubin, "Mortality and cancer incidence of aircraft maintenance workers exposed to trichloroethylene and other organic solvents and chemicals: extended follow up," Occupational and Environmental Medicine, vol. 55, no. 3, pp. 161-171, 1998.

[157] A. Anttila, E. Pukkala, M. Sallmen, S. Hernberg, and K. Hemminki, "Cancer incidence among Finnish workers exposed to halogenated hydrocarbons," Journal of Occupational and Environmental Medicine, vol. 37, no. 7, pp. 797-806, 1995.

[158] O. Axelson, A. Selden, K. Andersson, and C. Hogstedt, "Updated and expanded Swedish cohort study on trichloroethylene and cancer risk," Journal of Occupational Medicine, vol. 36, no. 5, pp. 556-562, 1994.

[159] J. H. Mandel, M. A. Kelsh, P. J. Mink et al., "Occupational trichloroethylene exposure and non-Hodgkin's lymphoma: a meta-analysis and review," Occupational and Environmental Medicine, vol. 63, no. 9, pp. 597-607, 2006.

[160] D. Wartenberg, D. Reyner, and C. S. Scott, "Trichloroethylene and cancer: epidemiologic evidence," Environmental Health Perspectives, vol. 108, supplement 2, pp. 161-176, 2000.

[161] M. P. Purdue, B. Bakke, P. Stewart et al., "A case-control study of occupational exposure to trichloroethylene and nonHodgkin lymphoma," Environmental Health Perspectives, vol. 119, no. 2, pp. 232-238, 2011.

[162] Q. Lan, L. Zhang, X. Tang et al., "Occupational exposure to trichloroethylene is associated with a decline in lymphocyte subsets and soluble CD27 and CD30 markers," Carcinogenesis, vol. 31, no. 9, pp. 1592-1596, 2010.

[163] Q. Lan, L. Zhang, G. Li et al., "Hematotoxicity in workers exposed to low levels of benzene," Science, vol. 306, no. 5702, pp. 1774-1776, 2004.

[164] G. S. Cooper, S. L. Makris, P. J. Nietert, and J. Jinot, "Evidence of autoimmune-related effects of trichloroethylene exposure from studies in mice and humans," Environmental Health Perspectives, vol. 117, no. 5, pp. 696-702, 2009.

[165] S. Ennaceur, D. Ridha, and R. Marcos, "Genotoxicity of the organochlorine pesticides 1,1-dichloro-2,2- bis(pchlorophenyl)ethylene (DDE) and hexachlorobenzene (HCB) in cultured human lymphocytes," Chemosphere, vol. 71, no. 7, pp. 1335-1339, 2008.

[166] S. P. Bhunya and G. B. Jena, "Genotoxic potential of the organochlorine insecticide lindane (gamma-BHC): an in vivo study in chicks," Mutation Research, vol. 272, no. 2, pp. 175$181,1992$.

[167] K. P. Cantor, A. Blair, G. Everett et al., "Pesticides and other agricultural risk factors for non-Hodgkin's lymphoma among men in Iowa and Minnesota," Cancer Research, vol. 52, no. 9, pp. 2447-2455, 1992.

[168] H. H. McDuffie, P. Pahwa, J. R. McLaughlin et al., "Non-Hodgkin's lymphoma and specific pesticide exposures inmen: cross-Canada study of pesticides and health," Cancer Epidemiology Biomarkers and Prevention, vol. 10, no. 11, pp. 1155-1163, 2001.

[169] J. F. Viel, N. Floret, E. Deconinck, J. F. Focant, E. De Pauw, and J. Y. Cahn, "Increased risk of non-Hodgkin lymphoma and serum organochlorine concentrations among neighbors of a municipal solid waste incinerator," Environment International, vol. 37, no. 2, pp. 449-453, 2011.

[170] P. J. E. Quintana, R. J. Delfino, S. Korrick et al., "Adipose tissue levels of organochlorine pesticides and polychlorinated biphenyls and risk of non-Hodgkin's lymphoma," Environmental Health Perspectives, vol. 112, no. 8, pp. 854-861, 2004.

[171] J. J. Spinelli, C. H. Ng, J. P. Weber et al., "Organochlorines and risk of non-Hodgkin lymphoma," International Journal of Cancer, vol. 121, no. 12, pp. 2767-2775, 2007.

[172] P. Cocco, P. Brennan, A. Ibba et al., "Plasma polychlorobiphenyl and organochlorine pesticide level and risk of major lymphoma subtypes," Occupational and Environmental Medicine, vol. 65, no. 2, pp. 132-140, 2008.

[173] K. P. Cantor, P. T. Strickland, J. W. Brock et al., "Risk of non-Hodgkin's lymphoma and prediagnostic serum organochlorines: $\beta$-Hexachlorocyclohexane, chlordane/ 
heptachlor-related compounds, dieldrin, and hexachlorobenzene," Environmental Health Perspectives, vol. 111, no. 2, pp. 179-183, 2003.

[174] F. Laden, K. A. Bertrand, L. Altshul, J. C. Aster, S. A. Korrick, and S. K. Sagiv, "Plasma organochlorine levels and risk of non-Hodgkin lymphoma in the nurses' health study," Cancer Epidemiology Biomarkers and Prevention, vol. 19, no. 5, pp. 1381-1384, 2010.

[175] D. Baris, S. H. Zahm, K. P. Cantor, and A. Blair, "Agricultural use of DDT and risk of non-Hodgkin's lymphoma: pooled analysis of three case-control studies in the United States," Occupational and Environmental Medicine, vol. 55, no. 8, pp. 522-527, 1998.

[176] L. S. Engel, F. Laden, A. Andersen et al., "Polychlorinated biphenyl levels in peripheral blood and non-Hodgkin's lymphoma: a report from three cohorts," Cancer Research, vol. 67 , no. 11, pp. 5545-5552, 2007.

[177] E. V. Brauner, M. Sorensen, E. Gaudreau et al., "A prospective study of organochlorines in adipose tissue and risk of nonHodgkin lymphoma," Environmental Health Perspectives, vol. 120, pp. 105-111, 2012.

[178] A. J. De Roos, S. H. Zahm, K. P. Cantor et al., "Integrative assessment of multiple pesticides as risk factors for nonHodgkin's lymphoma among men," Occupational and Environmental Medicine, vol. 60, no. 9, p. E11, 2003.

[179] A. D. Lieberman, M. R. Craven, H. A. Lewis, and J. H. Nemenzo, "Genotoxicity from domestic use of organophosphate pesticides," Journal of Occupational and Environmental Medicine, vol. 40, no. 11, pp. 954-957, 1998.

[180] C. Bolognesi, M. Peluso, P. Degan, R. Rabboni, A. Munnia, and A. Abbondandolo, "Genotoxic effects of the carbamate insecticide, methomyl. II. In vivo studies with pure compound and the technical formulation, "Lannate 25"', Environmental and Molecular Mutagenesis, vol. 24, no. 3, pp. 235-242, 1994.

[181] B. L. Waddell, S. H. Zahm, D. Baris et al., "Agricultural use of organophosphate pesticides and the risk of non-Hodgkin's lymphoma among male farmers (United States)," Cancer Causes and Control, vol. 12, no. 6, pp. 509-517, 2001.

[182] T. Zheng, S. H. Zahm, K. P. Cantor, D. D. Weisenburger, Y. Zhang, and A. Blair, "Agricultural exposure to carbamate pesticides and risk of non-Hodgkin lymphoma," Journal of Occupational and Environmental Medicine, vol. 43, no. 7, pp. 641-649, 2001.

[183] L. Miligi, A. S. Costantini, V. Bolejack et al., "Non-Hodgkin's lymphoma, leukemia, and exposures in agriculture: results from the Italian Multicenter Case-Control Study," American Journal of Industrial Medicine, vol. 44, no. 6, pp. 627-636, 2003.

[184] R. Mahajan, A. Blair, J. Coble et al., "Carbaryl exposure and incident cancer in the Agricultural Health Study," International Journal of Cancer, vol. 121, no. 8, pp. 17991805, 2007.

[185] B. P. Singh, L. Smghal, and R. S. Chauhan, "Immunotoxicity of carbaryl in chicken," Indian Journal of Experimental Biology, vol. 45, no. 10, pp. 890-895, 2007.

[186] L. Hardell, M. Eriksson, and M. Nordström, "Exposure to pesticides as risk factor for non-Hodgkin's lymphoma and hairy cell leukemia: pooled analysis of two Swedish casecontrol studies," Leukemia and Lymphoma, vol. 43, no. 5, pp. 1043-1049, 2002.

[187] M. Eriksson, L. Hardell, M. Carlberg, and M. Åkerman, "Pesticide exposure as risk factor for non-Hodgkin lymphoma including histopathological subgroup analysis," International Journal of Cancer, vol. 123, no. 7, pp. 1657-1663, 2008.

[188] L. Hardell and M. Eriksson, "A case-control study of nonHodgkin lymphoma and exposure to pesticides," Cancer, vol. 85, pp. 1353-1360, 1999.

[189] J. A. Rusiecki, A. De Roos, W. J. Lee et al., "Cancer incidence among pesticide applicators exposed to Atrazine in the agricultural health study," Journal of the National Cancer Institute, vol. 96, no. 18, pp. 1375-1382, 2004.

[190] L. E. Freeman, J. A. Rusiecki, J. A. Hoppin et al., "Atrazine and cancer incidence among pesticide applicators in the agricultural health study (1994-2007)," Environmental Health Perspectives, vol. 119, pp. 1253-1259, 2011.

[191] L. S. Engel, Q. Lan, and N. Rothman, "Polychlorinated biphenyls and non-Hodgkin lymphoma," Cancer Epidemiology Biomarkers and Prevention, vol. 16, no. 3, pp. 373-376, 2007.

[192] N. Rothman, K. P. Cantor, A. Blair et al., "A nested case-control study of non-Hodgkin lymphoma and serum organochlorine residues," The Lancet, vol. 350, no. 9073, pp. 240-244, 1997.

[193] A. J. De Roos, P. Hartge, J. H. Lubin et al., "Persistent organochlorine chemicals in plasma and risk of nonHodgkin's lymphoma," Cancer Research, vol. 65, no. 23, pp. 11214-11226, 2005.

[194] M. S. Wolff, D. Camann, M. Gammon, and S. D. Stellman, "Proposed PCB congener groupings for epidemiological studies," Environmental Health Perspectives, vol. 105, no. 1, pp. 13-14, 1997.

[195] S. Villeneuve, L. Orsi, A. Monnereau et al., "Increased frequency of hematopoietic malignancies In relatives of patients with lymphoid neoplasms: a French case-control study," International Journal of Cancer, vol. 124, no. 5, pp. 1188-1195, 2009.

[196] F. K. Mensah, E. V. Willett, P. Ansell, P. J. Adamson, and E. Roman, "Non-Hodgkin's lymphoma and family history of hematologic malignancy," American Journal of Epidemiology, vol. 165, no. 2, pp. 126-133, 2007.

[197] S. S. Wang, S. L. Slager, P. Brennan et al., "Family history of hematopoietic malignancies and risk of non-Hodgkin lymphoma (NHL): a pooled analysis of 10211 cases and 11905 controls from the International Lymphoma Epidemiology Consortium (InterLymph)," Blood, vol. 109, no. 8, pp. 34793488, 2007.

[198] E. A. Engels, "Infectious agents as causes of non-Hodgkin lymphoma," Cancer Epidemiology Biomarkers and Prevention, vol. 16, no. 3, pp. 401-404, 2007.

[199] L. Dal Maso and S. Franceschi, "Epidemiology of nonHodgkin lymphomas and other haemolymphopoietic neoplasms in people with AIDS," Lancet Oncology, vol. 4, no. 2, pp. 110-119, 2003.

[200] N. Crum-Cianflone, K. H. Hullsiek, V. Marconi et al., "Trends in the incidence of cancers among HIV-infected persons and the impact of antiretroviral therapy: a 20-year cohort study," Acquired Immune Deficiency Syndrome, vol. 23, no. 1, pp. 41-50, 2009.

[201] G. Gaidano, D. Capello, and A. Carbone, "The molecular basis of acquired immunodeficiency syndrome-related lymphomagenesis," Seminars in Oncology, vol. 27, no. 4, pp. 431$441,2000$.

[202] A. Carbone and A. Gloghini, "AIDS-related lymphomas: from pathogenesis to pathology," British Journal of Haematology, vol. 130, no. 5, pp. 662-670, 2005. 
[203] E. C. Breen, S. K. Hussain, L. Magpantay et al., "B-cell stimulatory cytokines and markers of immune activation are elevated several years prior to the diagnosis of systemic AIDS-associated non-Hodgkin B-cell lymphoma," Cancer Epidemiology Biomarkers and Prevention, vol. 20, no. 7, pp. 1303-1314, 2011.

[204] E. A. Engels, R. M. Pfeiffer, O. Landgren, and R. D. Moore, "Immunologic and virologic predictors of AIDS-related nonHodgkin lymphoma in the highly active antiretroviral therapy Era," Journal of Acquired Immune Deficiency Syndromes, vol. 54, no. 1, pp. 78-84, 2010.

[205] L. S. Young and A. B. Rickinson, "Epstein-Barr virus: 40 years on," Nature Reviews Cancer, vol. 4, no. 10, pp. 757-768, 2004.

[206] H. Hjalgrim and E. A. Engels, "Infectious aetiology of Hodgkin and non-Hodgkin lymphomas: a review of the epidemiological evidence," Journal of Internal Medicine, vol. 264, no. 6, pp. 537-548, 2008.

[207] H. E. Heslop, "Biology and treatment of Epstein-Barr virusassociated non-Hodgkin lymphomas," Hematology, pp. 260 266, 2005.

[208] N. Becker, M. O. Falster, C. M. Vajdic et al., "Selfreported history of infections and the risk of non-Hodgkin lymphoma: an InterLymph pooled analysis," International Journal of Cancer. In press.

[209] N. Becker, J. Fortuny, T. Alvaro et al., "Medical history and risk of lymphoma: results of a European case-control study (EPILYMPH)," Journal of Cancer Research and Clinical Oncology, vol. 135, no. 8, pp. 1099-1107, 2009.

[210] K. Arisawa, M. Soda, S. Endo et al., "Evaluation of adult T-cell leukemia/lymphoma incidence and its impact on non-Hodgkin lymphoma incidence in southwestern Japan," International Journal of Cancer, vol. 85, pp. 319-324, 2000.

[211] K. E. Foreman, P. E. Bacon, E. D. Hsi, and B. J. Nickoloff, "In situ polymerase chain reaction-based localization studies support role of human herpesvirus- 8 as the cause of two AIDS-related neoplasms: Kaposi's sarcoma and body cavity lymphoma," Journal of Clinical Investigation, vol. 99, no. 12, pp. 2971-2978, 1997.

[212] L. Wang, N. Wakisaka, C. C. Tomlinson et al., “The Kaposi's sarcoma-associated herpesvirus (KSHV/HHV-8) K1 protein induces expression of angiogenic and invasion factors," Cancer Research, vol. 64, no. 10, pp. 2774-2781, 2004.

[213] F. Marcucci and A. Mele, "Hepatitis viruses and nonHodgkin lymphoma: epidemiology, mechanisms of tumorigenesis, and therapeutic opportunities," Blood, vol. 117, no. 6, pp. 1792-1798, 2011.

[214] A. Mele, A. Pulsoni, E. Bianco et al., "Hepatitis C virus and B-cell non-Hodgkin lymphomas: an Italian multicenter casecontrol study," Blood, vol. 102, no. 3, pp. 996-999, 2003.

[215] A. S. Duberg, M. Nordström, A. Törner et al., "NonHodgkin's lymphoma and other nonhepatic malignancies in Swedish patients with hepatitis C virus infection," Hepatology, vol. 41, no. 3, pp. 652-659, 2005.

[216] L. A. Anderson and E. A. Engels, "Hepatitis C virus infection and non-Hodgkin lymphoma: interesting association or causal relationship?" International Journal of Cancer, vol. 122, no. 8, pp. 10-12, 2008.

[217] C. S. Rabkin, B. H. Tess, R. E. Christianson et al., "Prospective study of hepatitis $\mathrm{C}$ viral infection as a risk factor for subsequent B-cell neoplasia," Blood, vol. 99, no. 11, pp. 42404242, 2002.

[218] L. A. Anderson, R. Pfeiffer, J. L. Warren et al., "Hematopoietic malignancies associated with viral and alcoholic hepatitis,"
Cancer Epidemiology Biomarkers and Prevention, vol. 17, no. 11, pp. 3069-3075, 2008.

[219] L. Dal Maso and S. Franceschi, "Hepatitis C virus and risk of lymphoma and other lymphoid neoplasms: a meta-analysis of epidemiologic studies," Cancer Epidemiology Biomarkers and Prevention, vol. 15, no. 11, pp. 2078-2085, 2006.

[220] S. de Sanjose, Y. Benavente, C. M. Vajdic et al., "Hepatitis C and non-Hodgkin lymphoma among 4784 cases and 6269 controls from the international lymphoma epidemiology consortium," Clinical Gastroenterology and Hepatology, vol. 6, no. 4, pp. 451-458, 2008.

[221] J. P. Gisbert, L. García-Buey, J. M. Pajares, and R. MorenoOtero, "Systematic review: regression of lymphoproliferative disorders after treatment for hepatitis C infection," Alimentary Pharmacology and Therapeutics, vol. 21, no. 6, pp. 653662, 2005.

[222] J. G. Kusters, A. H. M. van Vliet, and E. J. Kuipers, "Pathogenesis of Helicobacter pylori infection," Clinical Microbiology Reviews, vol. 19, no. 3, pp. 449-490, 2006.

[223] J. Parsonnet, S. Hansen, L. Rodriguez et al., "Helicobacter pylori infection and gastric lymphoma," The New England Journal of Medicine, vol. 330, no. 18, pp. 1267-1271, 1994.

[224] X. Sagaert, E. Van Cutsem, G. De Hertogh, K. Geboes, and T. Tousseyn, "Gastric MALT lymphoma: a model of chronic inflammation-induced tumor development," Nature Reviews Gastroenterology and Hepatology, vol. 7, no. 6, pp. 336-346, 2010.

[225] S. Luminari, M. Cesaretti, L. Marcheselli et al., "Decreasing incidence of gastric MALT lymphomas in the era of antiHelicobacter pylori interventions: results from a populationbased study on extranodal marginal zone lymphomas," Annals of Oncology, vol. 21, no. 4, pp. 855-859, 2009.

[226] M. Q. Du, "MALT lymphoma : recent advances in aetiology and molecular genetics," Journal of Clinical and Experimental Hematopathology, vol. 47, no. 2, pp. 31-42, 2007.

[227] A. Martí, A. Marcos, and J. A. Martínez, "Obesity and immune function relationships," Obesity Reviews, vol. 2, no. 2, pp. 131-140, 2001.

[228] S. C. Larsson and A. Wolk, "Obesity and risk of nonHodgkin's lymphoma: a meta-analysis," International Journal of Cancer, vol. 121, no. 7, pp. 1564-1570, 2007.

[229] S. C. Larsson and A. Wolk, "Body mass index and risk of non-Hodgkin's and Hodgkin's lymphoma: a meta-analysis of prospective studies," European Journal of Cancer, vol. 47, no. 16, pp. 2422-2430, 2011.

[230] G. Maskarinec, E. Erber, J. Gill, W. Cozen, and L. N. Kolonel, "Overweight and obesity at different times in life as risk factors for non-Hodgkin's lymphoma: the multiethnic cohort," Cancer Epidemiology Biomarkers and Prevention, vol. 17, no. 1, pp. 196-203, 2008.

[231] R. D. Pylypchuk, L. J. Schouten, R. A. Goldbohm, H. C. Schouten, and P. A. van den Brandt, "Body mass index, height, and risk of lymphatic malignancies: a prospective cohort study," vol. 170, no. 3, pp. 297-307, 2009.

[232] L. A. Anderson, S. Gadalla, L. M. Morton et al., "Populationbased study of autoimmune conditions and the risk of specific lymphoid malignancies," International Journal of Cancer, vol. 125, no. 2, pp. 398-405, 2009.

[233] K. E. Smedby, C. M. Vajdic, M. Falster et al., "Autoimmune disorders and risk of non-Hodgkin lymphoma subtypes: a pooled analysis within the InterLymph Consortium," Blood, vol. 111, no. 8, pp. 4029-4038, 2008. 
[234] K. E. Smedby, H. Hjalgrim, J. Askling et al., "Autoimmune and chronic inflammatory disorders and risk of non-Hodgkin lymphoma by subtype," Journal of the National Cancer Institute, vol. 98, no. 1, pp. 51-60, 2006.

[235] E. A. Engels, J. R. Cerhan, M. S. Linet et al., "Immunerelated conditions and immune-modulating medications as risk factors for non-Hodgkin's lymphoma: a case-control study," American Journal of Epidemiology, vol. 162, no. 12, pp. 1153-1161, 2005.

[236] E. Zintzaras, M. Voulgarelis, and H. M. Moutsopoulos, "The risk of lymphoma development in autoimmune diseases: a meta-analysis," Archives of Internal Medicine, vol. 165, no. 20, pp. 2337-2344, 2005.

[237] K. C. Söderberg, F. Jonsson, O. Winqvist, L. Hagmar, and M. Feychting, "Autoimmune diseases, asthma and risk of haematological malignancies: a nationwide case-control study in Sweden," European Journal of Cancer, vol. 42, no. 17, pp. 3028-3033, 2006.

[238] E. Theander, G. Henriksson, O. Ljungberg, T. Mandl, R. Manthorpe, and L. T. H. Jacobsson, "Lymphoma and other malignancies in primary Sjögren's syndrome: a cohort study on cancer incidence and lymphoma predictors," Annals of the Rheumatic Diseases, vol. 65, no. 6, pp. 796-803, 2006.

[239] M. Kauppi, E. Pukkala, and H. Isomäki, "Elevated incidence of hematologic malignancies in patients with Sjogren's syndrome compared with patients with rheumatoid arthritis (Finland)," Cancer Causes and Control, vol. 8, no. 2, pp. 201204, 1997.

[240] M. Pertovaara, E. Pukkala, P. Laippala, A. Miettinen, and A. Pasternack, "A longitudinal cohort study of Finnish patients with primary Sjögren's syndrome: clinical, immunological, and epidemiological aspects," Annals of the Rheumatic Diseases, vol. 60, no. 5, pp. 467-472, 2001.

[241] S. Bernatsky, J. F. Boivin, L. Joseph et al., "An international cohort study of cancer in systemic lupus erythematosus," Arthritis and Rheumatism, vol. 52, no. 5, pp. 1481-1490, 2005.

[242] L. Björnådal, B. Löfström, L. Yin, I. E. Lundberg, and A. Ekbom, "Increased cancer incidence in a Swedish cohort of patients with systemic lupus erythematosus," Scandinavian Journal of Rheumatology, vol. 31, no. 2, pp. 66-71, 2002.

[243] M. L. Mearin, C. Catassi, N. Brousse et al., "European multi-centre study on coeliac disease and non-Hodgkin lymphoma," European Journal of Gastroenterology and Hepatology, vol. 18, no. 2, pp. 187-194, 2006.

[244] C. Catassi, E. Fabiani, G. Corrao et al., "Risk of non-Hodgkin lymphoma in celiac disease," Journal of the American Medical Association, vol. 287, no. 11, pp. 1413-1419, 2002.

[245] J. Askling, M. Linet, G. Gridley, T. S. Halstensen, K. Ekström, and A. Ekbom, "Cancer incidence in a population-based cohort of individuals hospitalized with celiac disease or dermatitis herpetiformis," Gastroenterology, vol. 123, no. 5, pp. 1428-1435, 2002.

[246] E. Thomas, D. H. Brewster, R. J. Black, and G. J. Macfarlane, "Risk of malignancy among patients with rheumatic conditions," International Journal of Cancer, vol. 88, pp. 497-502, 2000.

[247] K. Ekström, H. Hjalgrim, L. Brandt et al., "Risk of malignant lymphomas in patients with rheumatoid arthritis and in their first-degree relatives," Arthritis and Rheumatism, vol. 48, no. 4, pp. 963-970, 2003.

[248] K. E. Smedby, E. Baecklund, and J. Askling, "Malignant lymphomas in autoimmunity and inflammation: a review of risks, risk factors, and lymphoma characteristics," Cancer
Epidemiology Biomarkers and Prevention, vol. 15, no. 11, pp. 2069-2077, 2006.

[249] J. Delabie, H. Holte, J. M. Vose et al., "Enteropathy-associated T-cell lymphoma: clinical and histological findings from the international peripheral T-Cell lymphoma project," Blood, vol. 118, no. 1, pp. 148-155, 2011.

[250] M. Troch, S. Woehrer, B. Streubel et al., "Chronic autoimmune thyroiditis (Hashimoto's thyroiditis) in patients with MALT lymphoma," Annals of Oncology, vol. 19, no. 7, pp. 1336-1339, 2008.

[251] C. M. Vajdic, M. O. Falster, S. de Sanjose et al., "Atopic disease and risk of non-Hodgkin lymphoma: an interlymph pooled analysis," Cancer Research, vol. 69, no. 16, pp. 6482-6489, 2009.

[252] A. E. Grulich, C. M. Vajdic, J. M. Kaldor et al., "Birth order, atopy, and risk of non-Hodgkin lymphoma," Journal of the National Cancer Institute, vol. 97, no. 8, pp. 587-594, 2005.

[253] W. Cozen, J. R. Cerhan, O. Martinez-Maza et al., "The effect of atopy, childhood crowding, and other immune-related factors on non-Hodgkin lymphoma risk," Cancer Causes and Control, vol. 18, no. 8, pp. 821-831, 2007.

[254] N. Becker, S. de Sanjose, A. Nieters et al., "Birth order, allergies and lymphoma risk: results of the European collaborative research project Epilymph," Leukemia Research, vol. 31, no. 10, pp. 1365-1372, 2007.

[255] P. Vineis, R. Tumino, C. Vigano et al., "Delayed infection, family size and malignant lymphomas," Journal of Epidemiology and Community Health, vol. 54, no. 12, pp. 907-911, 2000.

[256] P. M. Bracci, T. B. Dalvi, and E. A. Holly, "Residential history, family characteristics and non-Hodgkin lymphoma, a population-based case-control study in the San Francisco Bay Area," Cancer Epidemiology Biomarkers and Prevention, vol. 15, no. 7, pp. 1287-1294, 2006.

[257] K. E. Smedby, H. Hjalgrim, E. T. Chang et al., "Childhood social environment and risk of non-Hodgkin lymphoma in adults," Cancer Research, vol. 67, no. 22, pp. 11074-11082, 2007.

[258] A. E. Grulich, C. M. Vajdic, M. O. Falster et al., "Birth order and risk of non-Hodgkin lymphoma-true association or bias?" American Journal of Epidemiology, vol. 172, no. 6, pp. 621-630, 2010.

[259] A. Altieri, F. Castro, J. L. Bermejo, and K. Hemminki, "Number of siblings and the risk of lymphoma, leukemia, and myeloma by histopathology," Cancer Epidemiology Biomarkers and Prevention, vol. 15, no. 7, pp. 1281-1286, 2006.

[260] J. R. Cerhan, T. M. Habermann, C. M. Vachon et al., "Menstrual and reproductive factors and risk of non-Hodgkin lymphoma: the Iowa Women's Health Study (United States)," Cancer Causes and Control, vol. 13, no. 2, pp. 131-136, 2002.

[261] Y. Zhang, T. R. Holford, B. Leaderer et al., "Menstrual and reproductive factors and risk of non-Hodgkin's lymphoma among connecticut women," American Journal of Epidemiology, vol. 160, no. 8, pp. 766-773, 2004.

[262] L. M. Morton, S. S. Wang, D. A. Richesson, A. Schatzkin, A. R. Hollenbeck, and J. V. Lacey, "Reproductive factors, exogenous hormone use and risk of lymphoid neoplasms among women in the National Institutes of Health-AARP Diet and Health Study Cohort," International Journal of Cancer, vol. 124, no. 11, pp. 2737-2743, 2009.

[263] Y. Lu, S. S. Wang, J. Sullivan-Halley et al., "Oral contraceptives, menopausal hormone therapy use and risk of B-cell non-Hodgkin lymphoma in the California Teachers Study," 
International Journal of Cancer, vol. 129, no. 4, pp. 974-982, 2011.

[264] K. H. Mildon, P. Ansell, E. Roman, and E. V. Kane, "Reproductive factors, menopausal hormone therapy, and risk of non-Hodgkin, diffuse large B-cell and follicular lymphomas: a UK case-control study," Cancer Causes and Control, vol. 21, no. 12, pp. 2079-2083, 2010.

[265] J. S. Lee, P. M. Bracci, and E. A. Holly, "Non-Hodgkin lymphoma in women: reproductive factors and exogenous hormone use," American Journal of Epidemiology, vol. 168, no. 3, pp. 278-288, 2008.

[266] E. V. Kane, E. Roman, N. Becker et al., "Menstrual and reproductive factors, and hormonal contraception use: associations with non-Hodgkin lymphoma in a pooled analysis of InterLymph case-control studies," Annals of Oncology, vol. 23, no. 9, pp. 2362-2374, 2012.

[267] L. Costas, D. Casabonne, Y. Benavente et al., "Reproductive factors and lymphoid neoplasms in Europe: findings from the EpiLymph case-control study," Cancer Causes and Control, vol. 23, pp. 195-206, 2012.

[268] H. O. Adami, S. Tsaih, M. Lambe et al., "Pregnancy and risk of non-Hodgkin's lymphoma: a prospective study," International Journal of Cancer, vol. 70, pp. 155-158, 1997.

[269] J. Prescott, Y. Lu, E. T. Chang et al., "Reproductive factors and non-Hodgkin lymphoma risk in the California teachers study," PLoS ONE, vol. 4, no. 12, Article ID e8135, 2009.

[270] R. A. Nelson, A. M. Levine, and L. Bernstein, "Reproductive factors and risk of intermediate- or high-grade B-cell nonHodgkin's lymphoma in women," Journal of Clinical Oncology, vol. 19, no. 5, pp. 1381-1387, 2001.

[271] E. Erber, U. Lim, G. Maskarinec, and L. N. Kolonel, "Common immune-related risk factors and incident nonHodgkin lymphoma: the multiethnic cohort," International Journal of Cancer, vol. 125, no. 6, pp. 1440-1445, 2009.

[272] J. R. Cerhan, R. B. Wallace, F. Dick et al., "Blood transfusions and risk of non-Hodgkin's lymphoma subtypes and chronic lymphocytic leukemia," Cancer Epidemiology Biomarkers and Prevention, vol. 10, no. 4, pp. 361-368, 2001.

[273] J. R. Cerhan, R. B. Wallace, A. R. Folsom et al., "Medical history risk factors for non-Hodgkin's lymphoma in older women," Journal of the National Cancer Institute, vol. 89, no. 4, pp. 314-318, 1997.

[274] J. Adami, O. Nyrén, R. Bergström et al., "Blood transfusion and non-Hodgkin lymphoma: lack of association," Annals of Internal Medicine, vol. 127, no. 5, pp. 365-371, 1997.

[275] R. A. Nelson, A. M. Levine, and L. Bernstein, "Blood transfusions and the risk of intermediate- or high-grade non-Hodgkin's lymphoma," Journal of the National Cancer Institute, vol. 90, no. 22, pp. 1742-1743, 1998.

[276] E. K. Maguire-Boston, V. Suman, S. J. Jacobsen et al., "Blood transfusion and risk of non-Hodgkin's lymphoma," American Journal of Epidemiology, vol. 149, no. 12, pp. 1113-1118, 1999.

[277] Y. Zhang, T. R. Holford, B. Leaderer et al., "Blood transfusion and risk of non-Hodgkin's lymphoma in connecticut women," American Journal of Epidemiology, vol. 160, no. 4, pp. 325-330, 2004.

[278] E. J. Chow and E. A. Holly, "Blood transfusions as a risk factor for non-Hodgkin's lymphoma in the San Francisco Bay Area: a population-based study," American Journal of Epidemiology, vol. 155, no. 8, pp. 725-731, 2002.

[279] L. Brandt, J. Brandt, H. Olsson, H. Anderson, and T. Möller, "Blood transfusion as a risk factor for non-Hodgkin lymphoma," British Journal of Cancer, vol. 73, no. 9, pp. 1148-1151, 1996.

[280] J. J. Castillo, S. Dalia, and S. K. Pascual, "Association between red blood cell transfusions and development of non-Hodgkin lymphoma: a meta-analysis of observational studies," Blood, vol. 116, no. 16, pp. 2897-2907, 2010.

[281] J. O. Bordin and M. A. Blajchman, "Immunosuppressive effects of allogeneic blood transfusions: implications for the patient with a malignancy," Hematology/Oncology Clinics of North America, vol. 9, no. 1, pp. 205-218, 1995.

[282] J. R. Cerhan, "Transfusion and NHL risk: a meta-answer?" Blood, vol. 116, no. 16, pp. 2863-2864, 2010.

[283] Y. Jiang, P. J. Villeneuve, A. Wielgosz, D. E. Schaubel, S. S. A. Fenton, and Y. Mao, "The incidence of cancer in a population-based cohort of Canadian heart transplant recipients," American Journal of Transplantation, vol. 10, no. 3, pp. 637-645, 2010.

[284] J. Adami, H. Gäbel, B. Lindelöf et al., "Cancer risk following organ transplantation: a nationwide cohort study in Sweden," British Journal of Cancer, vol. 89, no. 7, pp. 1221-1227, 2003.

[285] S. C. Quinlan, R. M. Pfeiffer, L. M. Morton, and E. A. Engels, "Risk factors for early-onset and late-onset posttransplant lymphoproliferative disorder in kidney recipients in the United States," American Journal of Hematology, vol. 86, no. 2, pp. 206-209, 2011.

[286] R. J. Faull, P. Hollett, and S. P. McDonald, "Lymphoproliferative disease after renal transplantation in Australia and New Zealand," Transplantation, vol. 80, no. 2, pp. 193-197, 2005.

[287] P. J. Villeneuve, D. E. Schaubel, S. S. Fenton, F. A. Shepherd, Y. Jiang, and Y. Mao, "Cancer incidence among Canadian kidney transplant recipients," American Journal of Transplantation, vol. 7, no. 4, pp. 941-948, 2007.

[288] J. Ying, P. J. Villeneuve, S. S. A. Fenton, D. E. Schaubel, L. Lilly, and M. Yang, "Liver transplantation and subsequent risk of Cancer: findings from a Canadian cohort study," Liver Transplantation, vol. 14, no. 11, pp. 1588-1597, 2008.

[289] J. Fortuny, S. de Sanjosé, N. Becker et al., "Statin use and risk of lymphoid neoplasms: results from the European casecontrol study EPILYMPH," Cancer Epidemiology Biomarkers and Prevention, vol. 15, no. 5, pp. 921-925, 2006.

[290] Y. Zhang, T. R. Holford, B. Leaderer et al., "Prior medical conditions and medication use and risk of non-Hodgkin lymphoma in connecticut United States women," Cancer Causes and Control, vol. 15, no. 4, pp. 419-428, 2004.

[291] C. Chao, L. Xu, D. I. Abrams et al., "HMG-CoA reductase inhibitors (statins) use and risk of non-Hodgkin lymphoma in HIV-positive persons," Acquired Immune Deficiency Syndrome, vol. 25, pp. 1771-1777, 2011.

[292] E. J. Jacobs, C. C. Newton, M. J. Thun, and S. M. Gapstur, "Long-term use of cholesterol-lowering drugs and cancer incidence in a large United States cohort," Cancer Research, vol. 71, no. 5, pp. 1763-1771, 2011.

[293] P. F. Coogan, L. Rosenberg, and B. L. Strom, "Statin use and the risk of 10 cancers," Epidemiology, vol. 18, no. 2, pp. 213219, 2007.

[294] K. Hindler, C. S. Cleeland, E. Rivera, and C. D. Collard, "The role of statins in cancer therapy," Oncologist, vol. 11, no. 3, pp. 306-315, 2006.

[295] J. R. Cerhan, K. E. Anderson, C. A. Janney, C. M. Vachon, T. E. Witzig, and T. M. Habermann, "Association of aspirin and other non-steroidal anti-inflammatory drug use with incidence of non-Hodgkin lymphoma," International Journal of Cancer, vol. 106, no. 5, pp. 784-788, 2003. 
[296] I. Kato, K. L. Koenig, R. E. Shore et al., "Use of antiinflammatory and non-narcotic analgesic drugs and risk of non-Hodgkin's lymphoma (NHL) (United States)," Cancer Causes and Control, vol. 13, no. 10, pp. 965-974, 2002.

[297] M. L. Rasmussen, H. Hjalgrim, D. Molgaard-Nielsen, J. Wohlfahrt, and M. Melbye, "Antibiotic use and risk of nonHodgkin lymphomas," International Journal of Cancer, vol. 131, no. 7, pp. E1158-E1165, 2012.

[298] I. Kato, K. L. Koenig, M. S. Baptiste et al., "History of antibiotic use and risk of non-Hodgkin's lymphoma (NHL)," International Journal of Cancer, vol. 107, no. 1, pp. 99-105, 2003.

[299] E. T. Chang, K. E. Smedby, H. Hjalgrim et al., "Medication use and risk of non-Hodgkin's lymphoma," American Journal of Epidemiology, vol. 162, no. 10, pp. 965-974, 2005.

[300] S. Bernatsky, J. L. Lee, and E. Rahme, "Non-Hodgkin's lymphoma-meta-analyses of the effects of corticosteroids and non-steroidal anti-inflammatories," Rheumatology, vol. 46, no. 4, pp. 690-694, 2007.

[301] J. A. Baker, J. R. Weiss, M. S. Czuczman, R. J. Menezes, C. B. Ambrosone, and K. B. Moysich, "Regular use of aspirin or acetaminophen and risk of non-Hodgkin lymphoma," Cancer Causes and Control, vol. 16, no. 3, pp. 301-308, 2005.

[302] Y. Zhang, P. F. Coogan, J. R. Palmer, B. L. Strom, and L. Rosenberg, "Risk of non-Hodgkin lymphoma and use of non-steroidal anti-inflammatory drugs," Cancer Detection and Prevention, vol. 30, no. 1, pp. 99-101, 2006.

[303] E. D. Flick, K. A. Chan, P. M. Bracci, and E. A. Holly, "Use of nonsteroidal antiinflammatory drugs and nonHodgkin lymphoma: a population-based case-control study," American Journal of Epidemiology, vol. 164, no. 5, pp. 497504, 2006.

[304] L. A. Anderson, G. Gridley, E. A. Engels et al., "Antibiotic use and risk of non-Hodgkin's lymphoma: a population-based case-control study," British Journal of Cancer, vol. 98, no. 1, pp. 161-164, 2008.

[305] A. B. Beiderbeck, E. A. Holly, M. C. J. M. Sturkenboom, J. W. W. Coebergh, B. H. C. Stricker, and H. G. M. Leufkens, "Prescription medications associated with a decreased risk of non-Hodgkin's lymphoma," American Journal of Epidemiology, vol. 157, no. 6, pp. 510-516, 2003.

[306] S. O. Dalton, A. H. Poulsen, M. Nørgaard, J. K. McLaughlin, C. Johansen, and S. Friis, "Tricyclic antidepressants and nonHodgkin lymphoma," Epidemiology, vol. 19, no. 4, pp. 546549, 2008.

[307] S. O. Dalton, C. Johansen, L. Mellemkjær et al., "Antidepressant medications and risk for cancer," Epidemiology, vol. 11, no. 2, pp. 171-176, 2000.

[308] J. Stebbing, T. Powles, S. Mandalia, M. Nelson, B. Gazzard, and M. Bower, "Use of antidepressants and risk of cancer in individuals infected with HIV," Journal of Clinical Oncology, vol. 26, no. 14, pp. 2305-2310, 2008.

[309] S. Bahl, M. Cotterchio, N. Kreiger, and N. Klar, "Antidepressant medication use and non-Hodgkin's lymphoma risk: no association," American Journal of Epidemiology, vol. 160, no. 6, pp. 566-575, 2004.

[310] Y. Chen, T. Zheng, Q. Lan et al., "Cytokine polymorphisms in Th1/Th2 pathway genes, body mass index, and risk of nonHodgkin lymphoma," Blood, vol. 117, no. 2, pp. 585-590, 2011.

[311] L. M. Morton, L. Bernstein, S. S. Wang et al., "Hair dye use, genetic variation in $\mathrm{N}$-acetyltransferase 1 (NAT1) and 2 (NAT2), and risk of non-Hodgkin lymphoma," Carcinogenesis, vol. 28, no. 8, pp. 1759-1764, 2007.
[312] J. S. Colt, N. Rothman, R. K. Severson et al., "Organochlorine exposure, immune gene variation, and risk of non-Hodgkin lymphoma," Blood, vol. 113, no. 9, pp. 1899-1905, 2009.

[313] X. Han, T. Zheng, Q. Lan et al., "Genetic polymorphisms in nitric oxide synthase genes modify the relationship between vegetable and fruit intake and risk of non-Hodgkin lymphoma," Cancer Epidemiology Biomarkers and Prevention, vol. 18, no. 5, pp. 1429-1438, 2009.

[314] K. H. Barry, Y. Zhang, Q. Lan et al., "Genetic variation in metabolic genes, occupational solvent exposure, and risk of non-Hodgkin lymphoma," American Journal of Epidemiology, vol. 173, no. 4, pp. 404-413, 2011.

[315] L. M. Morton, M. Schenk, D. W. Hein et al., "Genetic variation in $\mathrm{N}$-acetyltransferase 1 (NAT1) and 2 (NAT2) and risk of non-Hodgkin lymphoma," Pharmacogenetics and Genomics, vol. 16, no. 8, pp. 537-545, 2006.

[316] C. F. Skibola, J. D. Curry, and A. Nieters, "Genetic susceptibility to lymphoma," Haematologica, vol. 92, no. 7, pp. 960-969, 2007.

[317] N. Rothman, C. F. Skibola, S. S. Wang et al., "Genetic variation in TNF and IL10 and risk of non-Hodgkin lymphoma: a report from the InterLymph Consortium," Lancet Oncology, vol. 7, no. 1, pp. 27-38, 2006.

[318] C. F. Skibola, P. M. Bracci, A. Nieters et al., "Tumor necrosis factor (TNF) and lymphotoxin- $\alpha$ (LTA) polymorphisms and risk of non-Hodgkin lymphoma in the interLymph consortium," American Journal of Epidemiology, vol. 171, no. 3, pp. 267-276, 2010.

[319] K. E. Smedby, J. N. Foo, C. F. Skibola et al., "GWAS of follicular lymphoma reveals allelic heterogeneity at $6 \mathrm{p} 21.32$ and suggests shared genetic susceptibility with diffuse large B-cell lymphoma," PLoS Genetics, vol. 7, no. 4, Article ID e1001378, 2011.

[320] C. F. Skibola, P. M. Bracci, E. Halperin et al., "Genetic variants at 6 p21.33 are associated with susceptibility to follicular lymphoma," Nature Genetics, vol. 41, no. 8, pp. 873-875, 2009.

[321] L. Conde, E. Halperin, N. K. Akers et al., "Genome-wide association study of follicular lymphoma identifies a risk locus at 6p21.32," Nature Genetics, vol. 42, no. 8, pp. 661664, 2010.

[322] M. C. Di Bernardo, D. Crowther-Swanepoel, P. Broderick et al., "A genome-wide association study identifies six susceptibility loci for chronic lymphocytic leukemia," Nature Genetics, vol. 40, no. 10, pp. 1204-1210, 2008.

[323] D. Crowther-Swanepoel, P. Broderick, M. C. Di Bernardo et al., "Common variants at $2 \mathrm{q} 37.3,8 \mathrm{q} 24.21,15 \mathrm{q} 21.3$ and 16q24.1 influence chronic lymphocytic leukemia risk," Nature Genetics, vol. 42, no. 2, pp. 132-136, 2010.

[324] S. L. Slager, K. G. Rabe, S. J. Achenbach et al., "Genomewide association study identifies a novel susceptibility locus at 6p21.3 among familial CLL," Blood, vol. 117, no. 6, pp. 1911-1916, 2011.

[325] D. Crowther-Swanepoel, M. C. Di Bernardo, K. Jamroziak et al., "Common genetic variation at $15 \mathrm{q} 25.2$ impacts on chronic lymphocytic leukaemia risk," British Journal of Haematology, vol. 154, no. 2, pp. 229-233, 2011.

[326] D. Crowther-Swanepoel, M. Mansouri, A. Enjuanes et al., "Verification that common variation at 2q37.1, 6p25.3, 11q24.1, 15q23, and 19q13.32 influences chronic lymphocytic leukaemia risk," British Journal of Haematology, vol. 150, no. 4, pp. 473-479, 2010. 


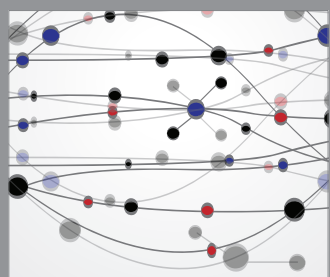

The Scientific World Journal
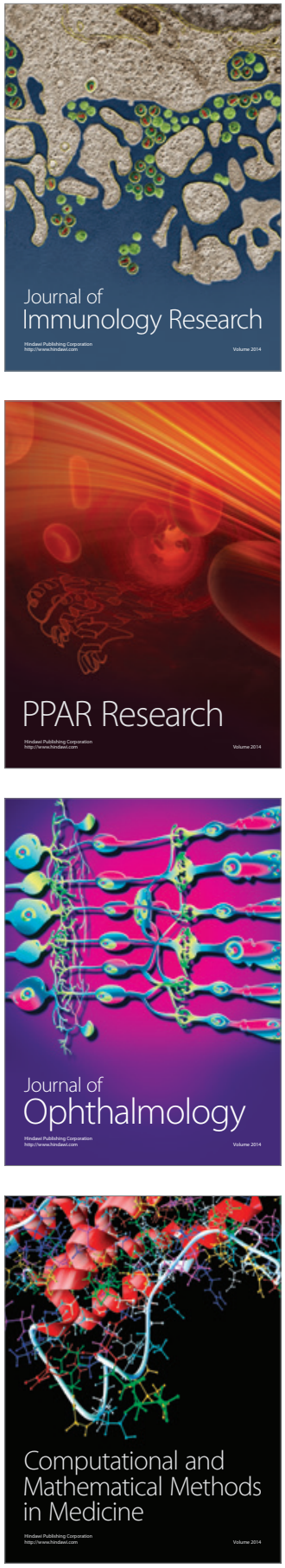

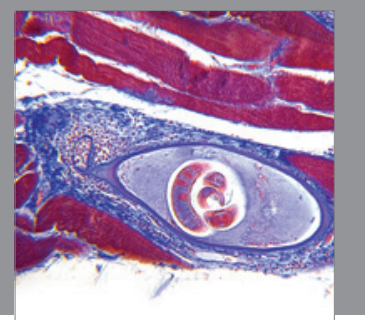

Gastroenterology

Research and Practice
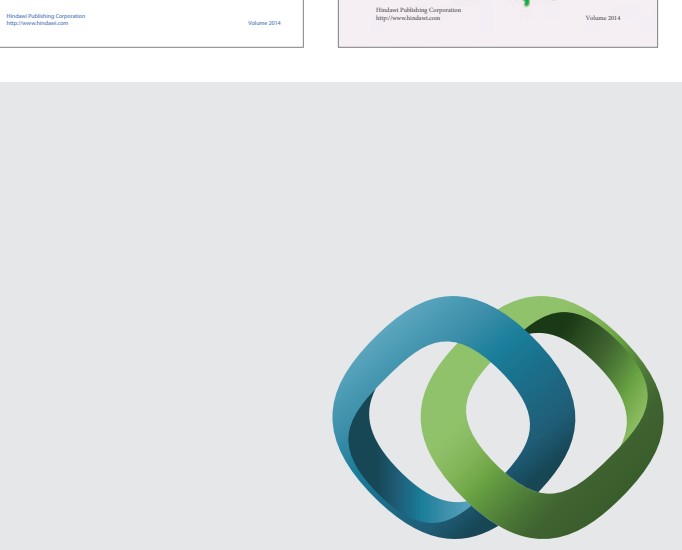

\section{Hindawi}

Submit your manuscripts at

http://www.hindawi.com
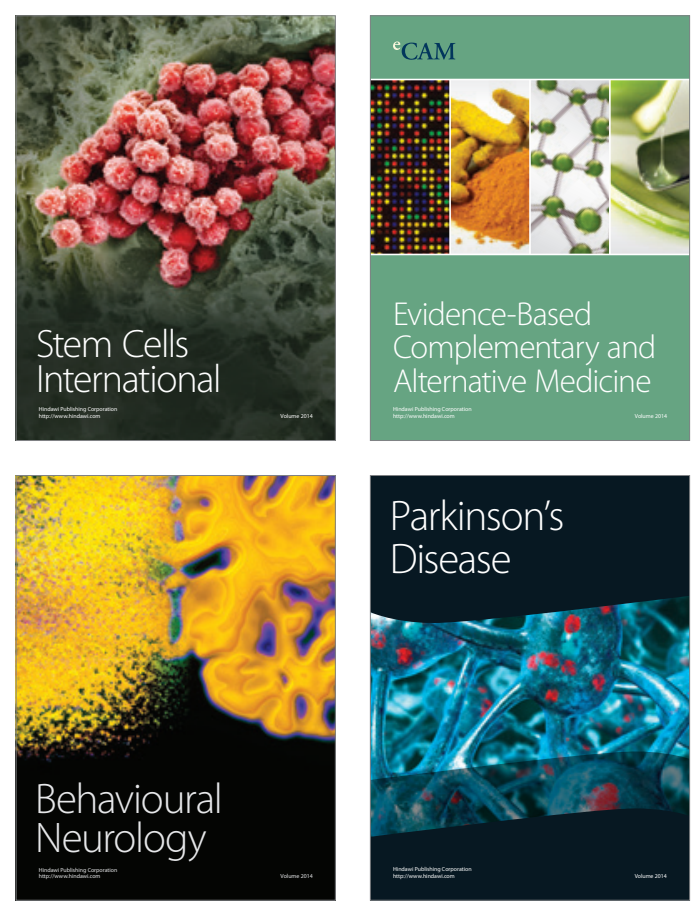

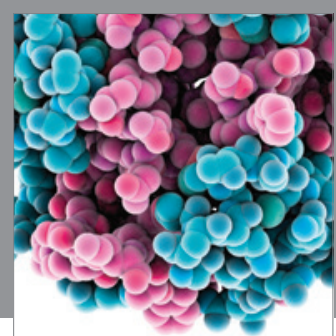

Journal of
Diabetes Research

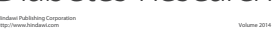

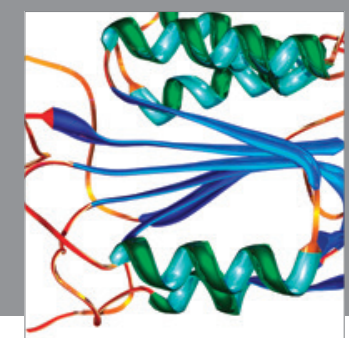

Disease Markers
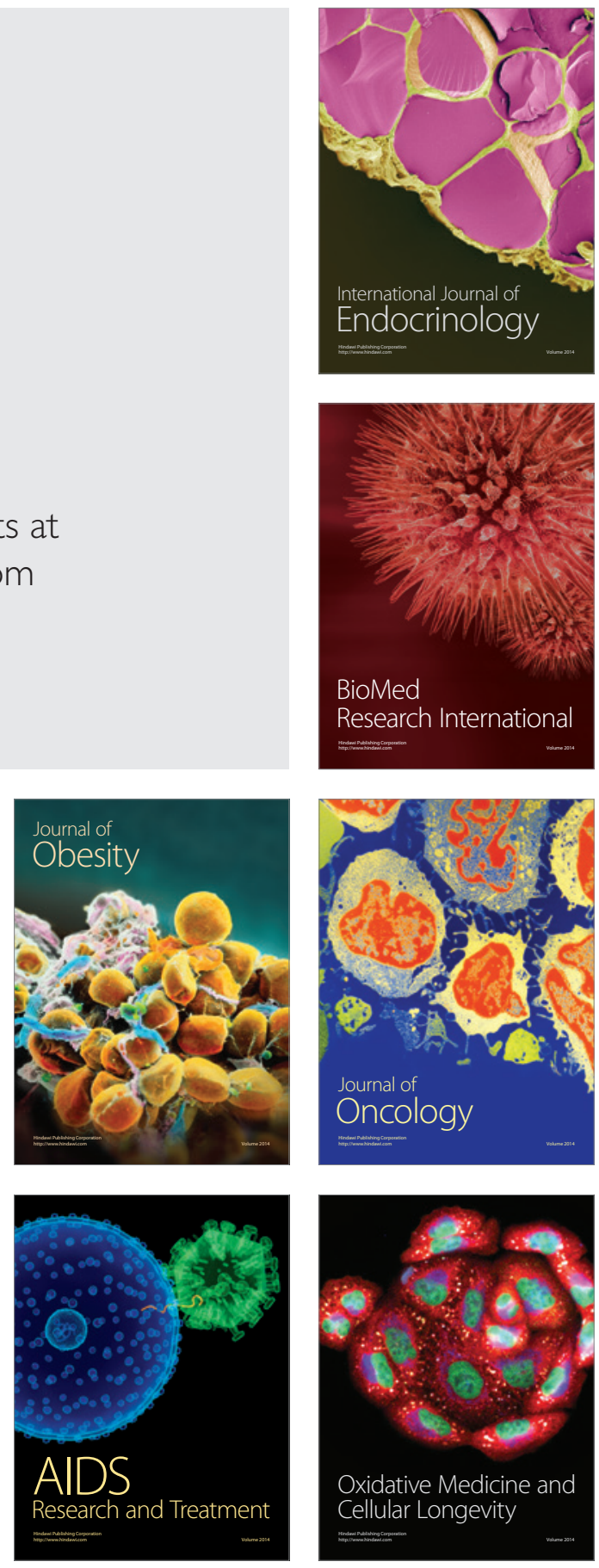